\title{
DNA Methylation Analysis Identifies Differentially Methylated Sites Associated with Early-Onset Intracranial Atherosclerotic Stenosis
}

\author{
Xin-Wei He ${ }^{1,2}$, Ying Zhao ${ }^{1,2}$, Yan-Hui Shi ${ }^{1,2}$, Rong Zhao ${ }^{1,2}$, Yi-Sheng Liu ${ }^{1,2}$, Yue Hu ${ }^{1,2}$, Mei-Ting Zhuang ${ }^{1,2}$, \\ Yi-Lan Wu ${ }^{1,2}$, Ge-Fei Li ${ }^{1,2}$, Jia-Wen Yin ${ }^{1,2}$, Guo-Hong Cui ${ }^{1,2}$ and Jian-Ren Liu ${ }^{1,2}$
}

Xin-Wei He, Ying Zhao, Yan-Hui Shi and Rong Zhao contributed equally to this work.

Guo-Hong Cui and Jian-Ren Liu are joint senior authors.

${ }^{1}$ Department of Neurology, Shanghai Ninth People's Hospital, Shanghai Jiao Tong University School of Medicine, Shanghai, China ${ }^{2}$ Clinical Research Center, Shanghai Jiao Tong University School of Medicine, Shanghai, China

Aim: Studies have suggested that genetic and environmental factors do not account for all risks and mechanisms of intracranial atherosclerotic stenosis (ICAS). DNA methylation may play a role in the progression of ICAS.

Methods: DNA methylation profiles of peripheral blood leucocytes from 7 patients with early-onset ICAS and 7 perfectly matched controls were interrogated for the first time using the Illumina Infinium Human MethylationEPIC BeadChip. Afterward, functional analysis for differentially methylated genes was conducted. In addition, pyrosequencing verification was performed in an independent cohort comprising 21 patients with earlyonset ICAS and 21 age- and gender-matched controls.

Results: A total of 318 cytosine-phosphate-guanine sites were found to be differentially methylated based on the established standards. Functional analysis annotated differentially methylated sites to atherosclerosis-related processes and pathways, such as the negative regulation of hydrolase activity (GO 0051346), type II diabetes mellitus (KEGG hsa04930), and the insulin signaling pathway (KEGG hsa04910). In addition, a differentially methylated site was also validated, cg22443212 in gene Rnf213, which showed significant hypermethylation in patients with early-onset ICAS compared with controls $59.56 \%(49.77 \%, 88.55 \%)$ vs. $44.65 \%$ (25.07\%, $53.21 \%$ ), respectively; $P=0.010$ ). Receiver operating characteristic curve analysis showed that the area under the curve value of $\operatorname{cg} 22443212$ was 0.744 ( $95 \%$ confidence interval, $0.586-0.866 ; P=0.002)$.

Conclusions: We revealed that altered DNA methylation may play a role in the occurrence and development of ICAS. These results provided new epigenetic insights into ICAS.

Key words: Intracranial atherosclerotic stenosis, Epigenetics, DNA methylation, Ring finger protein 213

\section{Introduction}

Intracranial atherosclerotic stenosis (ICAS) is an important etiology of ischemic stroke and a leading cause of recurrent stroke ${ }^{1)}$. Numerous studies have confirmed the racial differences in ICAS, and individuals of Asian, African, and Hispanic ancestry are at higher risk of ICAS ${ }^{2,3)}$. One favored hypothesis is that not only inherited susceptibility but also environmen- tal exposure plays a critical role in the pathogenesis of ICAS. However, despite intensive efforts at large genome-wide association studies and epidemiological studies, attempts to clearly identify all risks and mechanisms have been relatively disappointing.

Aberrant epigenetic modifications may bridge the environmental and genetic factors and thus lead to certain pathological consequences. DNA methylation, a stable and widely studied epigenetic event, is a pro-

Address for correspondence: Jian-Ren Liu, Department of Neurology, Shanghai Ninth People's Hospital, Shanghai Jiao Tong University School of Medicine, Shanghai, China E-mail: liujr021@sjtu.edu.cn

Received: October 21, 2018 Accepted for publication: April 2, 2019

Copyright@2020 Japan Atherosclerosis Society

This article is distributed under the terms of the latest version of CC BY-NC-SA defined by the Creative Commons Attribution License. 
cess by which a methyl group is added to a nucleotide, usually cytosine nucleotides, in the presence of cytosine-phosphate-guanine $(\mathrm{CpG})^{4)}$. DNA methylation can affect gene expression and chromatin organization $^{4)}$, and alterations in DNA methylation patterns might play a role in the progression of certain diseases $^{4,5)}$.

Both the global methylation status of the genome and aberrant methylation in certain specific methylated loci have been studied in several atherosclerotic lesions from extracranial carotid, coronary, or ascending aorta arteries ${ }^{6-8)}$. Furthermore, epigenome-wide association studies have linked peripheral blood cell DNA methylation profiles of specific loci to hyperlipidemia, hyperglycemia, and obesity, thus uncovering candidate circulating epigenetic markers of atherosclerosis ${ }^{9-11)}$.

The intracranial artery has been reported to have anatomically and physiologically distinct characteristics, such as the structure of the arterial walls and wall shear stress, compared with the extracranial carotid, coronary, or other systemic arteries ${ }^{12-14)}$. Studies on methylation profiling in patients with ICAS are limited. Since it is difficult to obtain intracranial vascular tissue, methylation signatures from the circulation of patients with ICAS hold promise as potential biomarkers that might be useful in clinical practice.

Age-related functional impairments are critical factors contributing to the risk and development of ICAS ${ }^{1,15)}$, and DNA methylation changes may be associated with the aging process ${ }^{8,15,16)}$. Thus, in order to reduce the influences of age-related dysfunction on both DNA methylation and ICAS, we performed this study focusing only on subjects with early-onset ICAS.

\section{Aim}

For the first time, we used a genome-wide DNA methylation analysis (Illumina Infinium Human MethylationEPIC BeadChip, Illumina Inc., San Diego, CA, USA) combined with pyrosequencing approaches to identify novel DNA methylation sites in peripheral blood leucocytes from patients with early-onset ICAS compared with those from controls.

\section{Materials and Methods}

\section{Ethics Statement}

This study was approved by the Ethics Committee of Shanghai Ninth People's Hospital, Shanghai Jiao Tong University School of Medicine. All procedures were performed in accordance with the ethical guidelines of the 1975 Declaration of Helsinki. Written informed consent was obtained from all partici- pants included in the study.

\section{Study Subjects}

The definition of early-onset ICAS is unspecific. In this study, we recruited patients aged younger than 60 years, according to several previously published studies on coronary artery or carotid atherosclerosis ${ }^{17,18)}$.

At the stage of chip interrogation, we enrolled 7 patients with ICAS and 7 controls. To eliminate interference from gene methylation induced by other factors as much as possible, we carefully screened and selected a similarly matched control for each patient. The matching factors included age, gender, and history of smoking, drinking, hypertension, diabetes, dyslipidemia, and drug use. In the pyrosequencing verification, a precise pair-match might not be possible, because we had only a limited number of controls for selection. Thus, the matching factors included just age and gender. There were no significant differences between the two groups with regard to demographic and clinical features (Supplementary Table 1).

The following inclusion criteria were applied: age $\leq 60$ years and intracranial artery atherosclerosis causing $\geq 50 \%$ stenosis in one or more major intracranial arteries ${ }^{19)}$. In addition, the exclusion criteria were extracranial atherosclerosis with significant stenosis $(\geq$ $50 \%$ ), hemorrhagic stroke or moyamoya disease (MMD), severe coronary heart disease (CHD) or arrhythmia, hyperthyroidism or hypothyroidism, hematological disease, severe hepatic or renal insufficiency, a history of tumors, chronic inflammation, recent infection, or recent surgery.

\section{Vascular Assessments}

Intracranial arteries were assessed by at least one of the following examinations: magnetic resonance angiography (MRA), computed tomography angiography (CTA), or digital subtraction angiography (DSA). We assessed the intracranial artery segments, including the intracranial internal carotid artery, anterior cerebral artery, middle cerebral artery, posterior cerebral artery, intracranial vertebral artery, and basilar artery, and if there was a reduction of $\geq 50 \%$ in luminal diameter of any of these arterial segments ${ }^{19)}$. The exact degree of stenosis was measured by comparing the diameter of the vessel at the site of stenosis (D stenosis) with the normal diameter of the vessel just distal to the stenosis ( $\mathrm{D}$ distal) using the following formula: \% stenosis $=[1-(\mathrm{D}$ stenosis $/ \mathrm{D}$ distal $)] \times$ $100 \%{ }^{19)}$. Two independent investigators blinded to the clinical information and results of the methylation assay read and verified all images. 
Blood and Baseline Data Collection and Definition

Fasting blood samples were collected from the participants in the morning after an overnight fast. Blood specimens were collected in EDTA-treated tubes and then stored at $-80^{\circ} \mathrm{C}$ before being assayed. All samples were thawed only once prior to use. Blood biochemistry tests (e.g., fasting blood glucose and blood lipids) were performed at the clinical laboratory in the hospital.

The clinical and demographic characteristics of the enrolled participants, such as gender, age, smoking and drinking status, history of disease, and medication, were recorded. All patients underwent standardized diagnostic tests. Hypertension was defined as a mean systolic blood pressure $>140 \mathrm{mmHg}$ and/or a mean diastolic blood pressure $>90 \mathrm{mmHg}$ at two measurements, or a medical history of anti-hypertensive drugs. Diabetes mellitus was defined as fasting blood glucose $>7.00 \mathrm{mmol} / \mathrm{L}$ or a medical history of glucose-lowering drugs. Dyslipidemia was defined as serum triglycerides $\geq 1.69 \mathrm{mmol} / \mathrm{L}$, low-density lipoprotein cholesterol $\geq 3.41 \mathrm{mmol} / \mathrm{L}$, or the use of lipidlowering drugs. Smoking was defined as smoking at the time of stroke or had quit smoking within 1 year, and drinking was defined as $>2$ standard alcoholic beverages consumed per day.

\section{DNA Extraction and Bisulfite Treatment}

Genomic DNA (gDNA) was extracted from leucocytes from venous blood samples using a QIAamp DNA Mini Kit (Qiagen, Hilden, Germany). The purity and concentrations of DNA samples were determined using a NanoDrop 1000 Spectrophotometer and Qubit 3.0 Fluorometer (Thermo Fisher Scientific, Waltham, MA, USA). The gDNA samples were bisulfite converted using an EZ DNA Methylation Kit (ZYMO Research, Irvine, CA, USA).

\section{Genome-Wide DNA Methylation Profiling}

DNA methylation assessment was performed using the Infinium Human MethylationEPIC BeadChip (Illumina Inc.) to interrogate more than 850,000 $\mathrm{CpG}$ positions across the genome. The raw image intensities of the hybridized arrays were scanned using an iScan SQ scanner (Illumina). The obtained raw data were processed and standardized using GenomeStudio software 2011.1 (Illumina), and the background method was chosen as the normalization method. Methylation values were estimated as $\beta$-values that range between 0 (completely unmethylated) and 1 (completely methylated). The experimental process and technical validation were performed according to the manufacturer's instructions.

\section{Differential Methylation Analysis}

A $t$-test was used to compare methylation profile differences between the two groups. For quality control, the CpG sites with missing values or the detection of $P>0.05$ in more than $90 \%$ of specimens were eliminated.

Single CpG sites with an absolute value of DiffScore $>13$ and an absolute $\delta(\beta)>0.17$ were considered differentially methylated loci. The DiffScore is a transformation of the $P$-value that provides directionality to the $P$-value based on the difference between the average signals in the patient group vs. the control group. The formula is as follows: DiffScore $=10^{*} \operatorname{sgn}(\delta$ $(\beta))^{*} \log 10(P), \delta(\beta)=\beta$ (patients) $-\beta$ (controls). For a $P$-value of 0.05 , DiffScore $= \pm 13$.

Gene Ontology (GO) and Kyoto Encyclopedia of Genes and Genomes (KEGG) Pathway Analyses

GO and KEGG analyses were applied to determine the roles of the differentially methylated genes.

The pathway data were extracted from two standard public pathway databases: KEGG (http://www. kegg.jp/kegg/pathway.html) and GO (www.geneontology.org). The GO terms and KEGG pathways were considered significantly enriched with unadjusted raw $P<0.05$ and ranged according to $-\log 10(P)$ from the lowest to the highest.

\section{Validation by Pyrosequencing}

Pyrosequencing assays were performed to validate the results obtained from $\mathrm{CpG}$ methylation analysis. Briefly, bisulfite-treated DNA was used for polymerase chain reactions (PCRs) with biotinylated primers using a PyroMark PCR kit (Qiagen). In addition, the biotinylated amplicons were purified to the final PCR product using Streptavidin Sepharose beads. The PCR product was bound to Streptavidin Sepharose HP (Amersham Biosciences, Uppsala, Sweden), and the Sepharose beads containing the immobilized PCR product were purified, washed and denatured using denaturation solution, and rewashed using a Pyrosequencing Vacuum Prep Tool (Pyrosequencing, Qiagen) as recommended by the manufacturer. Pyrosequencing reactions and methylation quantification were carried out on a PSQ96 HS System (Pyrosequencing, Qiagen) using appropriate reagents and protocols. Sequencing controls were included in each run to ensure the fidelity of the measurements. The forward and reverse PCR primers (from $5^{\prime}$ to $3^{\prime}$ ) used were GTGTTTTAGGTT'TGGTTAAGTTTAGTTT and ACCTTCAAAACAAACATACTCTT, and the sequencing primer (from $5^{\prime}$ to $3^{\prime}$ ) used was AGTTGTAGGAGTGGG. 
He et al.

Table 1. Baseline and clinical characteristics of the participants for DNA methylation beadchip

\begin{tabular}{|c|c|c|c|}
\hline Characteristic & $\begin{array}{l}\text { Patients } \\
(n=7)\end{array}$ & $\begin{array}{c}\text { Controls } \\
\quad(n=7)\end{array}$ & $P$ value \\
\hline \multicolumn{4}{|l|}{ Demographics } \\
\hline Age (years) & $54(53,56)$ & $59(55,59)$ & 0.535 \\
\hline Male (\%) & $6(85.7)$ & $6(85.7)$ & 1.000 \\
\hline Hypertension (\%) & $5(71.4)$ & $5(71.4)$ & 1.000 \\
\hline Diabetes mellitus (\%) & $1(14.3)$ & $1(14.3)$ & 1.000 \\
\hline Dyslipidaemia (\%) & 3 (42.9) & $3(42.9)$ & 1.000 \\
\hline Smoking (\%) & $6(85.7)$ & $6(85.7)$ & 1.000 \\
\hline Drinking (\%) & $2(28.6)$ & $2(28.6)$ & 1.000 \\
\hline $\mathrm{SBP}(\mathrm{mmHg})$ & $140(115,144)$ & $150(149,157)$ & 0.805 \\
\hline DBP $(\mathrm{mmHg})$ & $78(78,80)$ & $88(88,91)$ & 0.710 \\
\hline \multicolumn{4}{|l|}{ Laboratory parameters } \\
\hline $\mathrm{FBG}(\mathrm{mmol} / \mathrm{L})$ & $6.30(5.20,8.90)$ & $4.70(4.25,5.00)$ & 0.149 \\
\hline $\mathrm{TG}(\mathrm{mmol} / \mathrm{L})$ & $1.71(1.40,3.07)$ & $2.25(1.50,2.26)$ & 0.535 \\
\hline $\mathrm{TC}(\mathrm{mmol} / \mathrm{L})$ & $3.90(3.65,4.54)$ & $5.66(5.57,5.89)$ & 0.259 \\
\hline HDL-C (mmol/L) & $0.85(0.80,0.96)$ & $1.34(1.06,1.37)$ & 0.805 \\
\hline LDL-C (mmol/L) & $2.82(2.28,3.26)$ & $3.93(3.82,4.14)$ & 0.097 \\
\hline Homocysteine $(\mu \mathrm{mol} / \mathrm{L})$ & $15.70(9.10,19.00)$ & $8.60(8.15,11.40)$ & 0.945 \\
\hline Fibrinogen $(\mathrm{g} / \mathrm{L})$ & $1.98(1.66,2.14)$ & $2.33(2.29,2.57)$ & 0.610 \\
\hline $\mathrm{CRP}(\mathrm{mg} / \mathrm{L})$ & $3.90(3.40,5.41)$ & $3.30(3.16,3.30)$ & 0.234 \\
\hline Urea nitrogen $(\mathrm{mmol} / \mathrm{L})$ & $4.60(4.50,6.10)$ & $6.60(5.80,6.65)$ & 0.295 \\
\hline Uric acid $(\mu \mathrm{mol} / \mathrm{L})$ & $286.0(246.0,300.0)$ & $279.0(268.0,335.0)$ & 0.234 \\
\hline Creatinine $(\mu \mathrm{mol} / \mathrm{L})$ & $91.0(75.3,100.3)$ & $88.0(80.0,99.0)$ & 1.000 \\
\hline
\end{tabular}

Continuous variables are expressed as the mean \pm standard deviation or the median (interquartile range). Categorical values are presented as frequencies (percentages).

Abbreviations: SBP, systolic blood pressure; DBP, diastolic blood pressure; FBG, fasting blood glucose; TG, triglycerides; TC, total cholesterol; HDL-C, high-density lipoprotein cholesterol; LDL-C, low-density lipoprotein cholesterol; CRP, C-reactive protein.

\section{Statistical Analysis}

Data are presented as the mean \pm standard deviation or median (interquartile range) for continuous variables and as count and percentage for categorical variables. The Shapiro-Wilk test was used to test variables for normal distribution. Continuous data were analyzed using a Student's $t$-test (normal distribution) or the Mann-Whitney $U$ test (non-normal distribution). Categorical data were analyzed using Pearson's $\chi^{2}$ test or Fisher's exact test. Receiver operating characteristic (ROC) curve analysis was used to determine diagnostic accuracy, and the cut-off point was calculated by maximizing the sensitivity according to the Youden index. Statistical analyses were performed using SPSS 18.0 software (SPSS Inc., Chicago, IL, USA) or MedCalc 12.5 (MedCalc Software, Ostend, Belgium). A $P$-value $<0.05$ was considered to indicate statistical significance.

\section{Results}

Identifying Differential DNA Methylation Sites

We compared genome-wide DNA methylation profiles between the 7 patients with ICAS and the 7 matched controls. The basic characteristics of these subjects are summarized in Table 1 . There were no significant differences in terms of demographic data between the two groups.

A total of $866,091 \mathrm{CpG}$ sites that passed the quality control procedure were analyzed in this study. The scatterplot shows a high correlation of methylation levels between patients and controls (Fig. 1A). Principal component analysis showed that the majority of patients and controls could be divided into two clusters (Supplementary Fig. 1). The Manhattan plot showed the distribution of possible differentially methylated CpG sites on each chromosome (Supplementary Fig. 2).

Three hundred and eighteen differentially methylated CpG sites, including 183 hypermethylated sites 

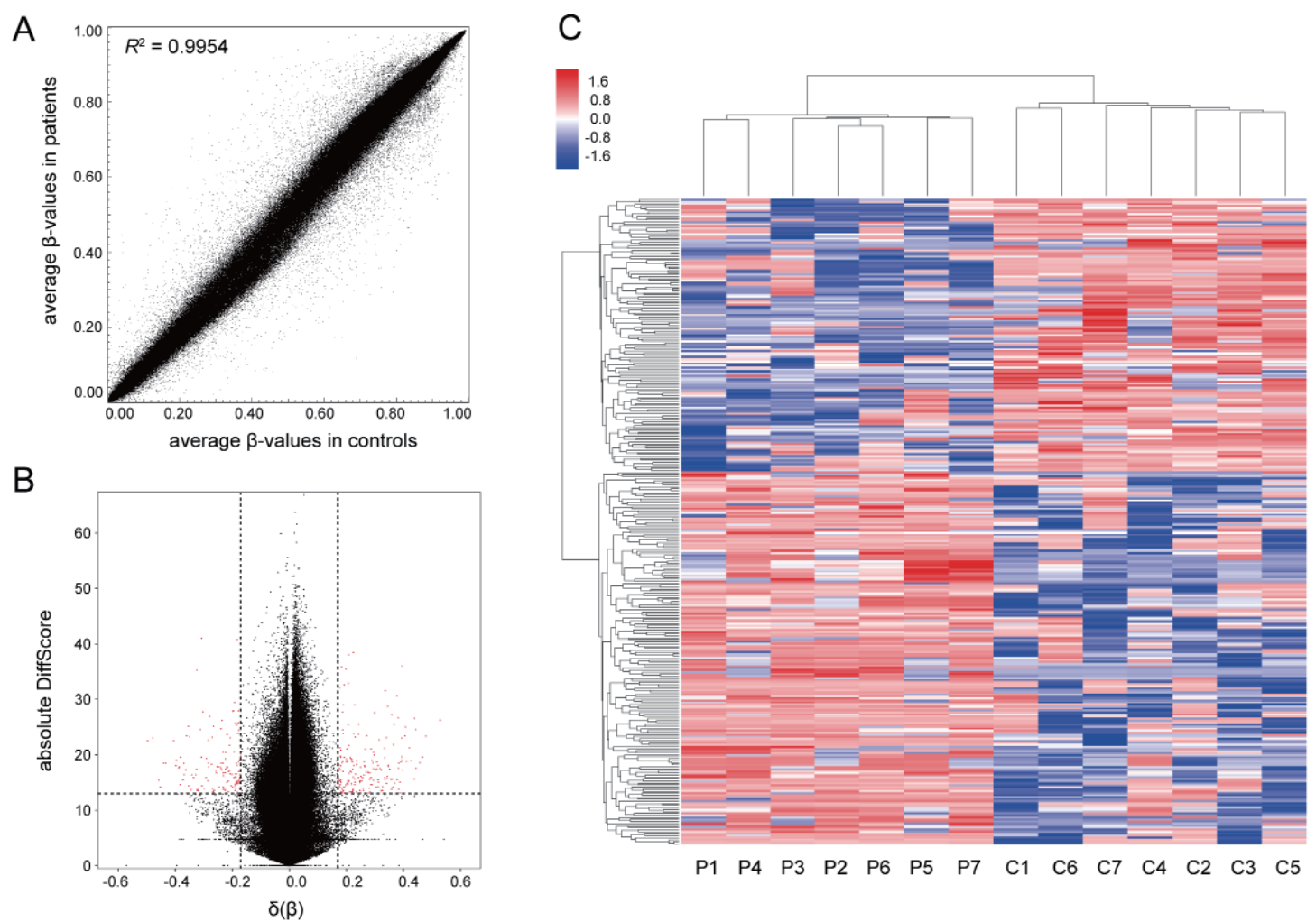

$\begin{array}{llllllllllllll}\text { P1 } & \text { P4 } & \text { P3 } & \text { P2 } & \text { P6 } & \text { P5 } & \text { P7 } & \text { C1 } & \text { C6 } & \text { C7 } & \text { C4 } & \text { C2 } & \text { C3 } & \text { C5 }\end{array}$

Fig. 1. Methylation profiles of patients with ICAS and controls

A: Scatterplots of probe intensities measuring the methylation level. X-and Y-axes represent the average $\beta$-values in subjects with ICAS and in controls, respectively. B: Volcano plots showing possible differentially methylated CpG sites. The $\mathrm{X}$-axis represents the magnitude of the difference in signal intensity between the groups for each probe in the microarray, expressed as $\delta(\beta)=\beta$ (patients) $-\beta$ (controls). The Y-axis represents the absolute DiffScore, and DiffScore $=10^{*} \operatorname{sgn}(\delta(\beta))^{*} \log 10(P)$. For a $P$-value of 0.05 , DiffScore $= \pm 13$. Significant differences (an absolute DiffScore $>13$ and an absolute $\delta(\beta)>0.17)$ are shown in red. C: Hierarchical cluster analysis of differentially methylated CpG sites identified in this study. The red color in the heat map denotes hypermethylated loci and the blue color denotes hypomethylated loci.

and 135 hypomethylated sites, were identified in patients compared with controls, based on the established standards (Supplementary Table 2; Fig. 1B); of these, 114 sites were located in or around $\mathrm{CpG}$ islands (within 4 kilobases of a CpG island). In addition, cluster analysis for different methylation profiles was performed using two-way hierarchical clustering (Fig. 1C).

\section{Functional Analysis}

We then assigned the changed methylation sites to known gene regions. Altogether, we identified 168 differentially methylated genes (Supplementary Table 3). To identify common functional characteristics of the differentially methylated genes, GO analysis for biological process terms and KEGG pathway analysis were performed. The differentially enrichment of GO terms and KEGG pathways were identified by unadjusted $P$. In addition, convincing evidence suggested that methylated $\mathrm{CpGs}$ near transcription start sites (TSSs) can directly cause gene silencing or even activation $^{20,21)}$. Thus, the genes in which differential methylation sites near the TSS (within $1500 \mathrm{bp}$ ) are located were also analyzed.

GO analysis for biological processes revealed that the top 4 terms are associated with inflammationrelated biological processes (Fig. 2A and Supplementary Table 4). Additionally, GO analysis for genes of the different sites near TSSs also supported the enrichment results (Fig.2B and Supplementary Table 5). In particular, the negative regulation of hydrolase activity (GO 0051346) was in the foremost findings in both GO analyses.

KEGG pathway analysis of differentially methylated genes revealed connections between the differentially methylated sites and the enrichment of glycometabolism-related pathways, that is, 3 of the top 5 pathways in the analysis for genes of all differentially meth- 
A

negative regulation of chemokine-mediated signaling pathway

Fc-gamma receptor signaling pathway involved in phagocytosis

negative regulation of hydrolase activity positive regulation of interleukin-13 secretion negative regulation of collateral sprouting toll-like receptor signaling pathway response to wounding skeletal system morphogenesis basement membrane organization fructose 6-phosphate metabolic process

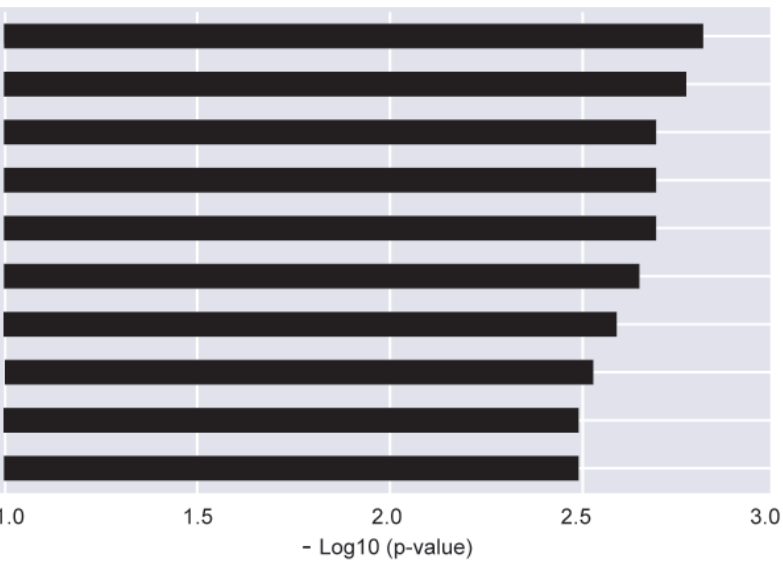

B

negative regulation of hydrolase activity

response to wounding actin cytoskeleton reorganization immune response negative regulation of angiogenesis insulin receptor signaling pathway negative regulation of type 2 immune response glial cell-derived neurotrophic factor receptor signaling pathway CD8-positive, alpha-beta T cell differentiation

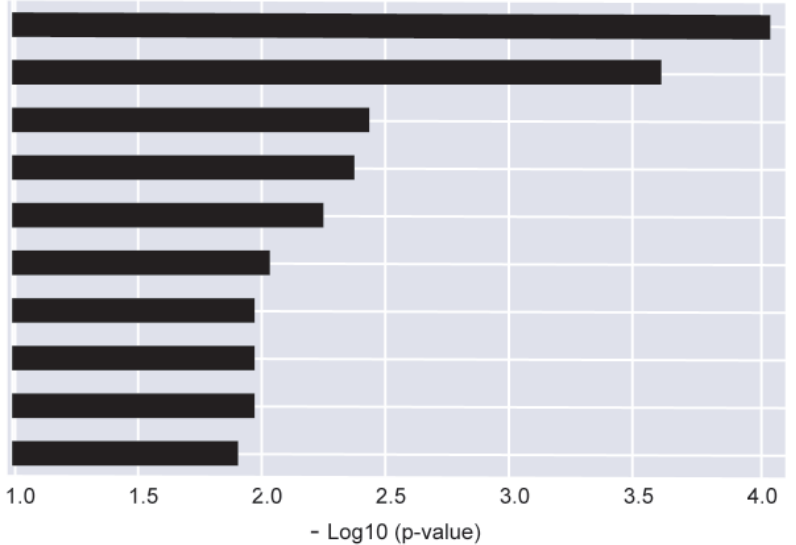

Fig. 2. Gene Ontology (GO) biological analysis of related genes that are associated with differentially methylated sites

The $\mathrm{X}$-axis represents the $P$-value and the $\mathrm{Y}$-axis represents the GO terms. A: For all differentially methylated sites. B: For differentially methylated sites near transcription start sites.

ylated sites and 4 of the top 5 pathways for genes of the different sites near TSSs (Fig. 3A and Fig. 3B, and Supplementary Table 6 and Table 7). In addition, type II diabetes mellitus (KEGG hsa04930) and the insulin signaling pathway (KEGG hsa04910) were in the top findings in both pathway analyses.

\section{Validation by Pyrosequencing}

Previous studies have reported that ring finger protein 213 (RNF213) is associated with intracranial vascular lesions ${ }^{22,23)}$, and we identified a methylation site, cg22443212, in the gene body of RNF213 (Rnf213) that showed significant hypermethylation in patients in the chip interrogation assay $[\delta(\beta)=0.201$ and DiffScore $=18.659]$. Thus, to verify the differential methylation of cg22443212, pyrosequencing was performed in an independent cohort comprising 21 patients with early-onset ICAS and 21 age- and gender-matched controls (Supplementary Table 1). Pyrosequencing analysis showed significant hypermethylation of $\operatorname{cg} 22443212$ in patients with ICAS compared with controls [59.56\% (49.77\%, 88.55\%) vs. $44.65 \%(25.07 \%, 53.21 \%) ; P=0.010$; Fig. $4 \mathrm{~A}]$, supporting the accuracy of the DNA methylation profile analysis results from the chip interrogation assay. Furthermore, the ROC curve analysis showed that the area under the curve value of $\operatorname{cg} 22443212$ that discriminated the presence of ICAS was 0.744 (95\% confidence interval, 0.586-0.866; $P=0.002$; Fig. 4B), and by the Youden index, the optimal cut-off value for cg22443212 as a diagnostic marker of stroke was $44.65 \%$, which yielded a sensitivity of $95.24 \%$ and a specificity of $52.38 \%$.

\section{Discussion}

To the best of our knowledge, this is the first study to reveal differential DNA methylation in patients with early-onset ICAS compared with controls. A total of $318 \mathrm{CpG}$ sites were found to be differentially methylated based on the established standards, suggesting an implication of methylation in 
A

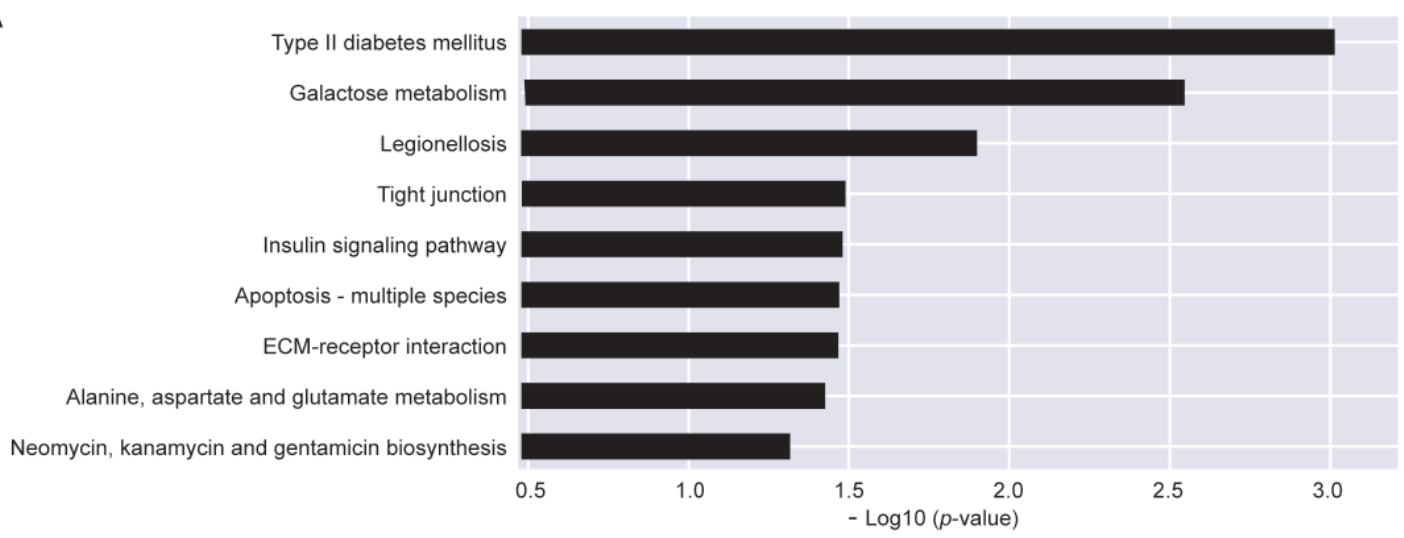

B

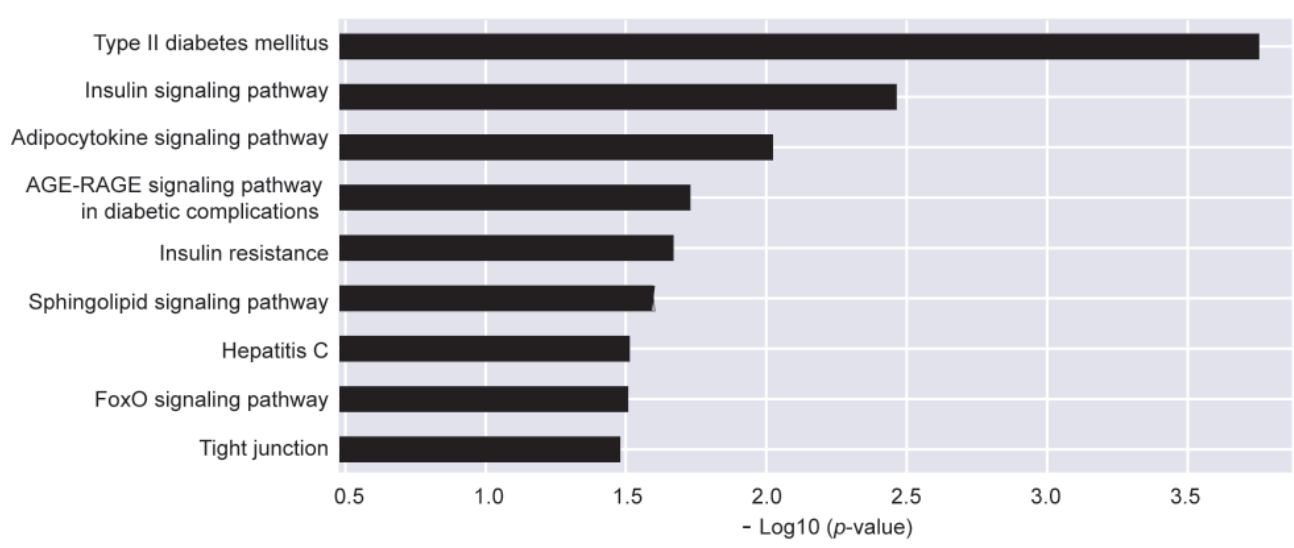

Fig. 3. Kyoto Encyclopedia of Genes and Genomes (KEGG) pathway analysis of related genes that are associated with differentially methylated sites

The $\mathrm{X}$-axis represents the $P$-value and the $\mathrm{Y}$-axis represents the pathways. A: For all differentially methylated sites. B: For differentially methylated sites near transcription start sites.
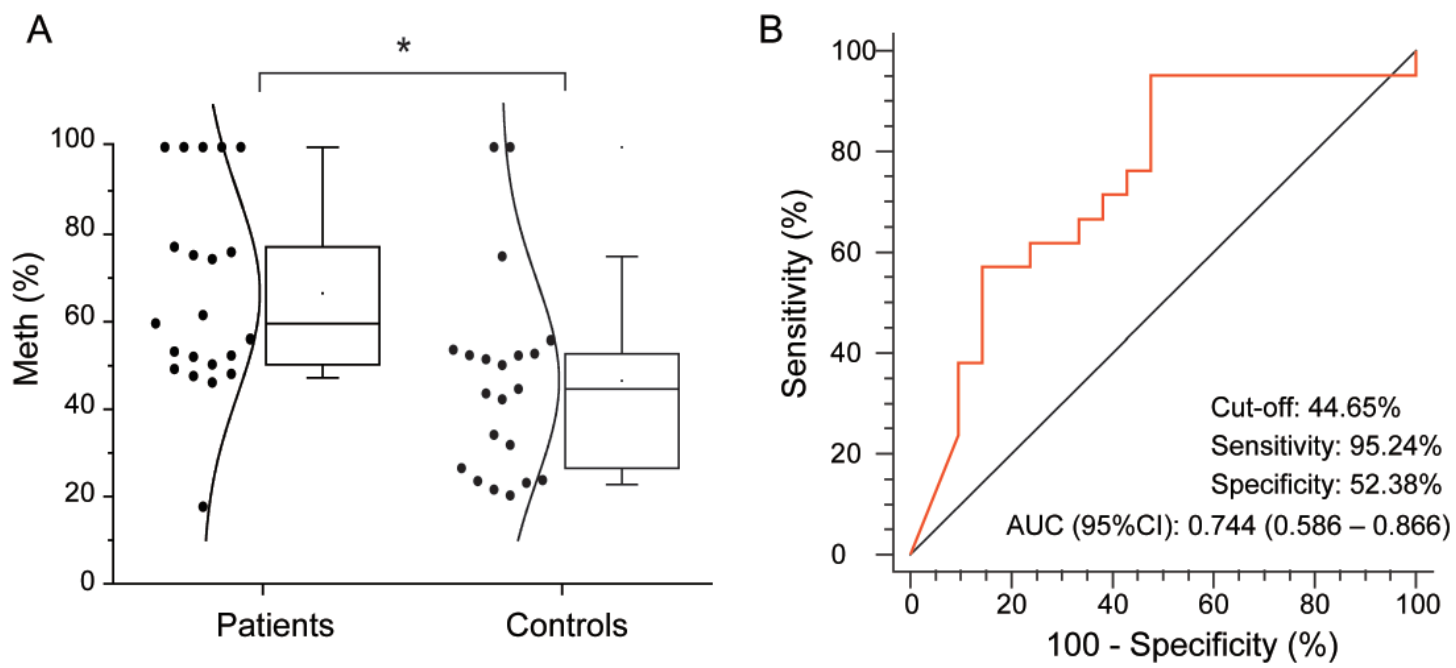

Fig. 4. Pyrosequencing assays validated the hypermethylation of cg22443212

A. Comparison of the methylation level of cg22443212 in patients with ICAS and controls. The black spots represent the actual value for each sample. In the box-and-whisker plots, the horizontal line in the middle of each box indicates the median value, the lower and upper ends of the box represent the 25th and 75th percentiles, respectively, and the peripheral whiskers represent the 10th and 90th percentiles. ${ }^{*} P<0.05$. B. Receiver operating characteristic curve analysis for cg22443212 to discriminate patients with ICAS. The figure shows the best predictive value according to the Youden index. Abbreviations: AUC, area under the curve; 95\% CI, 95\% confidence interval. 
ICAS. Functional analysis annotated differentially methylated sites to atherosclerosis-related processes. In addition, we also identified and validated a significantly hypermethylated site, $\mathrm{cg} 22443212$, in the gene Rnf 213 for the first time. The methylation level of cg22443212 showed significant diagnostic accuracy in discriminating patients from controls.

Indeed, there is a close connection between atherosclerosis and circulation, and peripheral blood leucocytes are ideal as they play vital roles in atherosclerosis ${ }^{24,25)}$. Accumulating evidence has illustrated the feasibility of DNA methylation profiling using peripheral blood to identify clinical correlations with surrogate markers of atherosclerosis in patients with atherosclerosis-related disease ${ }^{26-28)}$. In addition, studies have reported that the methylation status of some sites in atherosclerotic plaques is similar to blood from patients with extracranial carotid, coronary, or aorta artery atherosclerosis ${ }^{29,30}$. Moreover, animal studies have demonstrated that changes in the methylation level in peripheral blood and aortas of genetically atherosclerosis-prone mice precede the appearance of any histological sign of atherosclerosis ${ }^{31)}$. Thus, we postulate that differential methylation in blood leucocytes may serve as a potential biomarker in clinical practice to monitor the disease and associated comorbidities.

Atherosclerosis is considered a chronic inflammatory condition of the vessel wall. In our GO analysis for biological processes of differentially methylated genes, we further revealed the connections between inflammation-related biological processes and ICAS. For instance, the negative regulation of hydrolase activity was found in the foremost terms. Hydrolases carry out important degradative reactions in the body, cleaving large molecules into fragments that are used as a source of energy or for the excretion of waste materials. Abnormal hydrolase activity is certain to influence metabolic processes. For instance, the gene $P R K C Z$, encoding protein kinase $\mathrm{C} \zeta(\mathrm{PKC} \zeta)$, is a gene in the pathway of negative regulation of hydrolase activity found in our KEGG analysis. Accumulating studies suggested important roles of $\mathrm{PKC} \zeta$ in the process of atherosclerosis, such as regulating not only endothelial apoptosis but also tumor necrosis factor- $\alpha$ -induced endothelial inflammation ${ }^{32,33)}$, promoting monocyte adhesion by increased nuclear factor- $\kappa$ B-dependent intercellular adhesion molecule 1 expres$\operatorname{sion}^{33)}$, and participating in upregulating the expression of ATP-binding cassette transporter protein family member $\mathrm{A} 1$ and promoting cholesterol efflux in THP-1 macrophage-derived foam cells ${ }^{34)}$.

In KEGG pathway analysis, we found that the identified differentially methylated sites tended to be located in genes functionally related to glycometabo- lism, that is, the type II diabetes mellitus and the insulin signaling pathway. It is well known that atherosclerosis is one of the most severe complications associated with type 2 diabetes mellitus. Atherosclerosis occurs earlier and with greater severity in patients with diabetes, suggesting that abnormal glucose metabolism significantly accelerates rates of atherosclerosis. Although information on the methylation regulation of genes involved in the pathophysiology of ICAS is scant, the methylation of glycometabolism-related genes in other atherosclerotic diseases has been reported preliminarily ${ }^{12,21,22)}$. For instance, $G C K$, an encoded glucokinase that is a key enzyme of glucose phosphorylation, participates in the aforementioned pathways. A previous study has provided evidence that hypomethylation in the gene body of $G C K$ was significantly associated with the risk of $\mathrm{CHD}^{35)}$. The authors speculated that the decrease in GCK methylation in CHD cases may influence transcription and gene expression ${ }^{35)}$. Additionally, literature has suggested that defects in the insulin signaling pathway result in insulin resistance and contribute to metabolic dysfunction and cardiovascular disease ${ }^{34)}$. Recent studies have reported that the mechanism also involves methylation modification: high insulin levels reduce the methylation of leptin and adiponectin and induce the methylation of estrogen receptor $\alpha$, resulting in atherosclerosis ${ }^{34,36)}$.

Together, both biological processes and metabolic pathways of the genes of differentially methylated sites in our functional analysis are annotated to numerous atherosclerosis-related processes. Although particular DNA methylation studies of these processes have been limited up to now, methylation modification should represent an attractive molecular mechanism providing new insights into ICAS. Moreover, by comparing our results with other published methylation studies of atherosclerosis ${ }^{28)}$, we found that differences exist in both differentially methylated sites and functional analysis. These discrepancies highlight the differences in methylation involved in atherosclerosis between the intracranial artery and other systemic arteries. After all, different anatomical and physiological characteristics are known to exist ${ }^{12-14)}$. Further studies are warranted to unravel the mechanisms involved in methylation regulation.

In this study, pyrosequencing analysis validated the methylation status of $\operatorname{cg} 22443212$, a locus in the gene body of Rnf213, showing hypermethylation in patients with ICAS compared with controls, which was consistent with the finding in the methylation BeadChip analysis.

RNF213 is a protein with two consecutive $\mathrm{AAA}^{+}$ ATPase domains and one ring finger structure ${ }^{37)}$. Previous studies have found that RNF213 is linked to a 
variety of arterial wall development and remodeling processes and aberrant wall formation ${ }^{22,23)}$, although the exact molecular mechanisms by which RNF213 regulates the aforementioned processes remain largely unknown. The relationships of RNF213 with known molecular pathways of the remodeling vasculature, such as noncanonical WNT/Ca ${ }^{2+} / \mathrm{NFAT}$ signaling, have been revealed gradually ${ }^{38)}$. In addition, recent reports also showed that RNF213 is associated with immune and inflammatory responses in these processes $^{39,40)}$. Until now, no research on DNA methylation changes in $R n f 213$ has been reported. Several genetic polymorphisms in this gene have been linked to intracranial vascular lesions, such as $\mathrm{MMD}^{41,42)}$, non-MMD ICAS ${ }^{42-44)}$, and cerebral aneurysms ${ }^{45)}$. Interestingly, accumulating studies suggested that $R n f 213$ variants differ between early- and late-onset disorders ${ }^{41,46)}$, which shows that phenotypic heterogeneity in patients cannot be explained solely by gene dosage effects.

cg22443212 is located upstream of the coding area of $\mathrm{AAA}^{+}$ATPases and RING finger domains. RNF213 has two $\mathrm{AAA}^{+}$ATPase modules; the first module is essential for assembling RNF213 oligomers, whereas the second module is essential for the disassembly of RNF213 oligomers ${ }^{37)}$. Conformational changes in modules are assumed to be related to RNF213 function ${ }^{37}{ }^{47}$ ). In addition, a considerable amount of data supported the idea that the RING finger domain possibly acts as a ubiquitin ligase that covalently modifies substrate proteins with ubiquitin and stimulates intracellular biological processes ${ }^{37,48)}$. Based on previous and present study results, it is reasonable to infer that the hypermethylation of cg22443212 might affect the expression of the downstream genetic information, for example, by blocking the binding of transcription factors or methyl-binding proteins, thus altering the function and/or activity of RNF213. Of course, the precise molecular mechanism by which DNA methylation of $R n f 213$ causes human ICAS needs further investigation. In all, our findings, together with previously published susceptible mutation sites of $R n f 213$, suggest that there might be many more genetic or epigenetic abnormalities of Rnf 213 in ICAS, and whether these polymorphisms affect gene expression related to DNA methylation needs further studies.

There are several limitations in our study. First, intracranial arteries were assessed by MRA, CTA, or DSA. Different methods may lead to differences in severity assessments. In fact, all the patients received CTA and/or DSA. It has been demonstrated that CTA has high sensitivity and specificity for detecting $\geq 50 \%$ stenosis of large intracranial arterial segments com- pared to DSA ${ }^{49)}$. Second, we measured DNA methylation levels in peripheral blood leucocytes rather than in vessels. DNA methylation patterns are largely conserved across tissues and individuals ${ }^{50)}$. In addition, considering that harvesting intracranial arteries from a human body is impractical, the research strategy used in this study was ethical and logical. Third, due to the relatively small sample size analyzed in our study, aberrant methylation sites were not analyzed with clinical parameters, and functional analysis were not adjusted using the False discovery rate FDR-controlling procedures or the Bonferroni correction. Besides, differences in DNA collection without adjustments of celltype composition may bring in additional systematic biases ${ }^{51)}$. Thus, larger sample sizes are required in future studies. Nevertheless, this study constitutes the first preliminary identification of DNA methylation patterns in patients with ICAS and may help us to understand ICAS-associated genetic-epigenetic interactions.

\section{Conclusion}

In conclusion, the present study is a preliminary exploration of DNA methylation in patients with early-onset ICAS and controls. Overall, differentially methylated sites, corresponding genes, and associated biological processes and pathways were identified on the basis of the Infinium Human MethylationEPIC BeadChip interrogation and functional analysis, providing direct evidence that DNA methylation might play an important role in the occurrence and development of ICAS. In addition, we also identified and validated a significantly hypermethylated site in the gene $R n f 213$ for the first time, supporting the functional relevance of methylation of Rnf 213 in ICAS. In the future, studies that further validate the differential methylation of $\mathrm{CpG}$ sites are needed.

\section{Conflict of Interest}

The authors declare no conflicts of interest.

\section{Grant Support}

This work was supported by the Biomedicine Key program of the Shanghai Municipal Science and Technology Commission [No. 16411953100 to J.-R. Liu], the National Natural Science Foundation of China [No. 31400838 to G.-H. Cui and No. 81271302 to J.-R. Liu], a science popularization project and research innovation project from the Shanghai Municipal Science and Technology Commission [No. $18 \mathrm{dz} 2313603$ and No. 14JC1404300 to J.-R. Liu], 
the "Prevention and Control of Chronic Diseases Project" of Shanghai Hospital Development Center [No. SHDC12015310 to J.-R. Liu], a project from Shanghai Municipal Education Commission-Gaofeng Clinical Medicine Grant Support [No. 20161422 to J.-R. Liu], and the Clinical Research Project from Shanghai Jiao Tong University School of Medicine [No. DLY201614 to J.-R. Liu].

\section{References}

1) Gorelick PB, Wong KS, Bae HJ and Pandey DK: Large artery intracranial occlusive disease: a large worldwide burden but a relatively neglected frontier. Stroke, 2008; 39: 2396-2399

2) $\mathrm{Pu}$ Y, Lan L, Leng X, Wong LK and Liu L: Intracranial atherosclerosis: From anatomy to pathophysiology. Int J Stroke, 2017; 12: 236-245

3) Wang Y, Zhao X, Liu L, Soo YO, Pu Y, Pan Y, Wang Y, Zou X, Leung TW, Cai Y, Bai Q, Wu Y, Wang C, Pan X, Luo B and Wong KS: Prevalence and outcomes of symptomatic intracranial large artery stenoses and occlusions in China: the Chinese Intracranial Atherosclerosis (CICAS) Study. Stroke, 2014; 45: 663-669

4) Suzuki MM and Bird A: DNA methylation landscapes: provocative insights from epigenomics. Nat Rev Genet, 2008; 9: 465-476

5) Heyn $\mathrm{H}$ and Esteller M: DNA methylation profiling in the clinic: applications and challenges. Nat Rev Genet, 2012; 13: 679-692

6) Valencia-Morales Mdel P, Zaina S, Heyn H, Carmona FJ, Varol N, Sayols S, Condom E, Ramirez-Ruz J, Gomez A, Moran S, Lund G, Rodriguez-Rios D, Lopez-Gonzalez G, Ramirez-Nava M, de la Rocha C, Sanchez-Flores A and Esteller M: The DNA methylation drift of the atherosclerotic aorta increases with lesion progression. BMC Med Genomics, 2015; 8: 015-0085

7) Jiang YZ, Manduchi E, Stoeckert CJ, Jr. and Davies PF: Arterial endothelial methylome: differential DNA methylation in athero-susceptible disturbed flow regions in vivo. BMC Genomics, 2015; 16: 015-1656

8) Horvath S, Gurven M, Levine ME, Trumble BC, Kaplan H, Allayee H, Ritz BR, Chen B, Lu AT, Rickabaugh TM, Jamieson BD, Sun D, Li S, Chen W, Quintana-Murci L, Fagny M, Kobor MS, Tsao PS, Reiner AP, Edlefsen KL, Absher D and Assimes TL: An epigenetic clock analysis of race/ethnicity, sex, and coronary heart disease. Genome Biol, 2016; 17: 016-1030

9) Irvin MR, Zhi D, Joehanes R, Mendelson M, Aslibekyan S, Claas SA, Thibeault KS, Patel N, Day K, Jones LW, Liang L, Chen BH, Yao C, Tiwari HK, Ordovas JM, Levy D, Absher D and Arnett DK: Epigenome-wide association study of fasting blood lipids in the Genetics of Lipidlowering Drugs and Diet Network study. Circulation, 2014; 130: 565-572

10) Dick KJ, Nelson CP, Tsaprouni L, Sandling JK, Aissi D, Wahl S, Meduri E, Morange PE, Gagnon F, Grallert H, Waldenberger M, Peters A, Erdmann J, Hengstenberg C, Cambien F, Goodall AH, Ouwehand WH, Schunkert H,
Thompson JR, Spector TD, Gieger C, Tregouet DA, Deloukas P and Samani NJ: DNA methylation and bodymass index: a genome-wide analysis. Lancet, 2014; 383: 1990-1998

11) Hidalgo B, Irvin MR, Sha J, Zhi D, Aslibekyan S, Absher D, Tiwari HK, Kabagambe EK, Ordovas JM and Arnett DK: Epigenome-wide association study of fasting measures of glucose, insulin, and HOMA-IR in the Genetics of Lipid Lowering Drugs and Diet Network study. Diabetes, 2014; 63: 801-807

12) D'Armiento FP, Bianchi A, de Nigris F, Capuzzi DM, D’Armiento MR, Crimi G, Abete P, Palinski W, Condorelli $\mathrm{M}$ and Napoli C: Age-related effects on atherogenesis and scavenger enzymes of intracranial and extracranial arteries in men without classic risk factors for atherosclerosis. Stroke, 2001; 32: 2472-2479

13) Napoli C, Witztum JL, de Nigris F, Palumbo G, D'Armiento FP and Palinski W: Intracranial arteries of human fetuses are more resistant to hypercholesterolemiainduced fatty streak formation than extracranial arteries. Circulation, 1999; 99: 2003-2010

14) Zaina S, Goncalves I, Carmona FJ, Gomez A, Heyn H, Mollet IG, Moran S, Varol N and Esteller M: DNA methylation dynamics in human carotid plaques after cerebrovascular events. Arterioscler Thromb Vasc Biol, 2015; 35: 1835-1842

15) Soriano-Tarraga C, Mola-Caminal M, Giralt-Steinhauer E, Ois A, Rodriguez-Campello A, Cuadrado-Godia E, Gomez-Gonzalez A, Vivanco-Hidalgo RM, FernandezCadenas I, Cullell N, Roquer J and Jimenez-Conde J: Biological age is better than chronological as predictor of 3-month outcome in ischemic stroke. Neurology, 2017; 89: $830-836$

16) Horvath $S$ and Raj K: DNA methylation-based biomarkers and the epigenetic clock theory of ageing. Nat Rev Genet, 2018; 19: 371-384

17) $\mathrm{Xu} \mathrm{S,} \mathrm{Cheng} \mathrm{J,} \mathrm{Li} \mathrm{NH,} \mathrm{Chen} \mathrm{YN,} \mathrm{Cai} \mathrm{MY,} \mathrm{Tang} \mathrm{SS,}$ Huang H, Zhang B, Cen JM, Yang XL, Chen C, Liu X and Xiong XD: The association of APOC4 polymorphisms with premature coronary artery disease in a Chinese Han population. Lipids Health Dis, 2015; 14: 0150065

18) Suwa M, Imoto T, Kida A, Yokochi T, Iwase $M$ and Kozawa K: Association of body flexibility and carotid atherosclerosis in Japanese middle-aged men: a cross-sectional study. BMJ Open, 2018; 8: e019370

19) Chimowitz MI, Kokkinos J, Strong J, Brown MB, Levine SR, Silliman S, Pessin MS, Weichel E, Sila CA, Furlan AJ and et al.: The Warfarin-Aspirin Symptomatic Intracranial Disease Study. Neurology, 1995; 45: 1488-1493

20) Han W, Shi M and Spivack SD: Site-specific methylated reporter constructs for functional analysis of DNA methylation. Epigenetics, 2013; 8: 1176-1187

21) Bahar Halpern K, Vana T and Walker MD: Paradoxical role of DNA methylation in activation of FoxA2 gene expression during endoderm development. J Biol Chem, 2014; 289: 23882-23892

22) Sonobe S, Fujimura M, Niizuma K, Nishijima $Y$, Ito A, Shimizu H, Kikuchi A, Arai-Ichinoi N, Kure S and Tominaga $\mathrm{T}$ : Temporal profile of the vascular anatomy evaluated by 9.4-T magnetic resonance angiography and histo- 
pathological analysis in mice lacking RNF213: a susceptibility gene for moyamoya disease. Brain Res, 2014; 13: 64-71

23) Liu W, Morito D, Takashima S, Mineharu Y, Kobayashi $\mathrm{H}$, Hitomi T, Hashikata H, Matsuura N, Yamazaki S, Toyoda A, Kikuta K, Takagi Y, Harada KH, Fujiyama A, Herzig R, Krischek B, Zou L, Kim JE, Kitakaze M, Miyamoto S, Nagata K, Hashimoto N and Koizumi A: Identification of RNF213 as a susceptibility gene for moyamoya disease and its possible role in vascular development. PLoS One, 2011; 6: e22542

24) Lu X: Impact of Macrophages in Atherosclerosis. Curr Med Chem, 2016; 23: 1926-1937

25) Badimon L, Storey RF and Vilahur G: Update on lipids, inflammation and atherothrombosis. Thromb Haemost, 2011; 105: 11-0717

26) Zhao J, Forsberg CW, Goldberg J, Smith NL and Vaccarino $\mathrm{V}$ : MAOA promoter methylation and susceptibility to carotid atherosclerosis: role of familial factors in a monozygotic twin sample. BMC Med Genet, 2012; 13 : $1471-2350$

27) Guarrera S, Fiorito G, Onland-Moret NC, Russo A, Agnoli C, Allione A, Di Gaetano C, Mattiello A, Ricceri F, Chiodini P, Polidoro S, Frasca G, Verschuren MWM, Boer JMA, Iacoviello L, van der Schouw YT, Tumino R, Vineis P, Krogh V, Panico S, Sacerdote C and Matullo G: Gene-specific DNA methylation profiles and LINE-1 hypomethylation are associated with myocardial infarction risk. Clin Epigenetics, 2015; 7: 015-0164

28) Fernandez-Sanles A, Sayols-Baixeras S, Subirana I, Degano IR and Elosua R: Association between DNA methylation and coronary heart disease or other atherosclerotic events: A systematic review. Atherosclerosis, 2017; 263: 325-333

29) Istas G, Declerck K, Pudenz M, Szic KSV, Lendinez-Tortajada V, Leon-Latre M, Heyninck K, Haegeman G, Casasnovas JA, Tellez-Plaza M, Gerhauser C, Heiss C, Rodriguez-Mateos A and Berghe WV: Identification of differentially methylated BRCA1 and CRISP2 DNA regions as blood surrogate markers for cardiovascular disease. Sci Rep, 2017; 7: 017-03434

30) Kucher AN, Nazarenko MS, Markov AV, Koroleva IA and Barbarash OL: Variability of Methylation Profiles of CpG Sites in microrNA Genes in Leukocytes and Vascular Tissues of Patients with Atherosclerosis. Biochemistry, 2017; 82: 698-706

31) Lund G, Andersson L, Lauria M, Lindholm M, Fraga MF, Villar-Garea A, Ballestar E, Esteller M and Zaina S: DNA methylation polymorphisms precede any histological sign of atherosclerosis in mice lacking apolipoprotein E. J Biol Chem, 2004; 279: 29147-29154

32) Abe J and Berk BC: Novel mechanisms of endothelial mechanotransduction. Arterioscler Thromb Vasc Biol, 2014; 34: 2378-2386

33) Nigro P, Abe J, Woo CH, Satoh K, McClain C, O’Dell MR, Lee H, Lim JH, Li JD, Heo KS, Fujiwara K and Berk BC: PKCzeta decreases eNOS protein stability via inhibitory phosphorylation of ERK5. Blood, 2010; 116: 1971-1979

34) Kuang HJ, Zhao GJ, Chen WJ, Zhang M, Zeng GF, Zheng XL and Tang CK: Hsp27 promotes ABCA1 expression and cholesterol efflux through the PI3K/PKCzeta/Sp1 pathway in THP-1 macrophages. European journal of pharmacology, 2017; 810: 57-62

35) Xu L, Zheng D, Wang L, Jiang D, Liu H, Xu L, Liao Q, Zhang L, Liu P, Shi X, Wang Z, Sun L, Zhou Q, Li N, Huang Y, Le Y, Ye M, Shao G and Duan S: GCK genebody hypomethylation is associated with the risk of coronary heart disease. Biomed Res Int, 2014: 151723

36) Garcia-Cardona MC, Huang F, Garcia-Vivas JM, LopezCamarillo C, Del Rio Navarro BE, Navarro Olivos E, Hong-Chong E, Bolanos-Jimenez F and Marchat LA: DNA methylation of leptin and adiponectin promoters in children is reduced by the combined presence of obesity and insulin resistance. International journal of obesity (2005), 2014; 38: 1457-1465

37) Morito D, Nishikawa K, Hoseki J, Kitamura A, Kotani Y, Kiso K, Kinjo M, Fujiyoshi Y and Nagata K: Moyamoya disease-associated protein mysterin/RNF213 is a novel AAA + ATPase, which dynamically changes its oligomeric state. Sci Rep, 2014; 4:4442

38) Scholz B, Korn C, Wojtarowicz J, Mogler C, Augustin I, Boutros M, Niehrs C and Augustin HG: Endothelial RSPO3 Controls Vascular Stability and Pruning through Non-canonical WNT/Ca(2+)/NFAT Signaling. Dev Cell, 2016; 36: 79-93

39) Ohkubo K, Sakai Y, Inoue $H$, Akamine S, Ishizaki $Y$, Matsushita Y, Sanefuji M, Torisu H, Ihara K, Sardiello M and Hara T: Moyamoya disease susceptibility gene RNF213 links inflammatory and angiogenic signals in endothelial cells. Sci Rep, 2015; 5:13191

40) Kanoke A, Fujimura M, Niizuma K, Fujimura T, Kakizaki A, Ito A, Sakata H, Sato-Maeda M, Kure S and Tominaga T: Temporal profile of magnetic resonance angiography and decreased ratio of regulatory $\mathrm{T}$ cells after immunological adjuvant administration to mice lacking RNF213, a susceptibility gene for moyamoya disease. Brain Res, 2016; 1: 1-9

41) Duan L, Wei L, Tian Y, Zhang Z, Hu P, Wei Q, Liu S, Zhang J, Wang Y, Li D, Yang W, Zong R, Xian P, Han C, Bao X, Zhao F, Feng J, Liu W, Cao W, Zhou G, Zhu C, Yu F, Yang W, Meng Y, Wang J, Chen X, Wang Y, Shen B, Zhao B, Wan J, Zhang F, Zhao G, Xu A, Zhang X, Liu J, Zuo X and Wang K: Novel Susceptibility Loci for Moyamoya Disease Revealed by a Genome-Wide Association Study. Stroke, 2018; 49: 11-18

42) Miyawaki S, Imai H, Takayanagi S, Mukasa A, Nakatomi $\mathrm{H}$ and Saito N: Identification of a genetic variant common to moyamoya disease and intracranial major artery stenosis/occlusion. Stroke, 2012; 43: 3371-3374

43) Miyawaki S, Imai H, Shimizu M, Yagi S, Ono H, Mukasa A, Nakatomi H, Shimizu T and Saito N: Genetic variant RNF213 c. $14576 \mathrm{G}>\mathrm{A}$ in various phenotypes of intracranial major artery stenosis/occlusion. Stroke, 2013; 44: 2894-2897

44) Bang OY, Chung JW, Cha J, Lee MJ, Yeon JY, Ki CS, Jeon P, Kim JS and Hong SC: A Polymorphism in RNF213 Is a Susceptibility Gene for Intracranial Atherosclerosis. PLoS One, 2016; 11: e0156607

45) Zhou S, Ambalavanan A, Rochefort D, Xie P, Bourassa CV, Hince P, Dionne-Laporte A, Spiegelman D, Gan-Or Z, Mirarchi C, Zaharieva V, Dupre N, Kobayashi H, 
Hitomi T, Harada K, Koizumi A, Xiong L, Dion PA and Rouleau GA: RNF213 Is Associated with Intracranial Aneurysms in the French-Canadian Population. Am J Hum Genet, 2016; 99: 1072-1085

46) Miyatake S, Miyake N, Touho H, Nishimura-Tadaki A, Kondo Y, Okada I, Tsurusaki Y, Doi H, Sakai H, Saitsu H, Shimojima K, Yamamoto T, Higurashi M, Kawahara N, Kawauchi H, Nagasaka K, Okamoto N, Mori T, Koyano S, Kuroiwa Y, Taguri M, Morita S, Matsubara Y, Kure $S$ and Matsumoto N: Homozygous c. $14576 \mathrm{G}>\mathrm{A}$ variant of RNF213 predicts early-onset and severe form of moyamoya disease. Neurology, 2012; 78: 803-810

47) Kobayashi H, Matsuda Y, Hitomi T, Okuda H, Shioi H, Matsuda T, Imai H, Sone M, Taura D, Harada KH, Habu T, Takagi Y, Miyamoto S and Koizumi A: Biochemical and Functional Characterization of RNF213 (Mysterin) R4810K, a Susceptibility Mutation of Moyamoya Disease, in Angiogenesis In Vitro and In Vivo. J Am Heart Assoc, 2015; 4: 002146
48) Deshaies RJ and Joazeiro CA: RING domain E3 ubiquitin ligases. Annu Rev Biochem, 2009; 78: 399-434

49) Nguyen-Huynh MN, Wintermark M, English J, Lam J, Vittinghoff E, Smith WS and Johnston SC: How accurate is CT angiography in evaluating intracranial atherosclerotic disease? Stroke, 2008; 39: 1184-1188

50) Byun HM, Siegmund KD, Pan F, Weisenberger DJ, Kanel G, Laird PW and Yang AS: Epigenetic profiling of somatic tissues from human autopsy specimens identifies tissue- and individual-specific DNA methylation patterns. Hum Mol Genet, 2009; 18: 4808-4817

51) Shiwa Y, Hachiya T, Furukawa R, Ohmomo H, Ono K, Kudo H, Hata J, Hozawa A, Iwasaki M, Matsuda K, Minegishi N, Satoh M, Tanno K, Yamaji T, Wakai K, Hitomi J, Kiyohara Y, Kubo M, Tanaka H, Tsugane S, Yamamoto M, Sobue K and Shimizu A: Adjustment of Cell-Type Composition Minimizes Systematic Bias in Blood DNA Methylation Profiles Derived by DNA Collection Protocols. PLoS One, 2016; 11: e0147519 


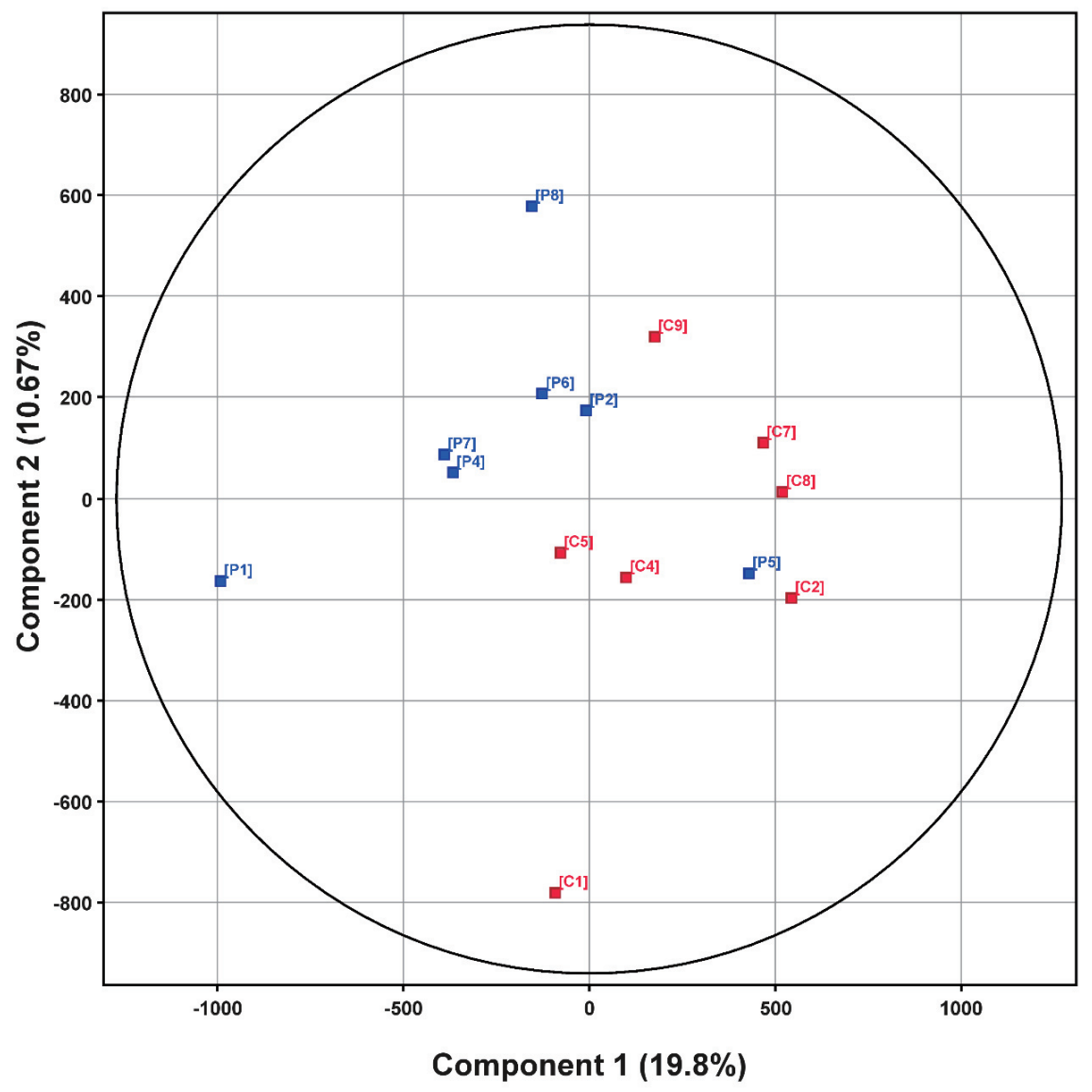

Supplementary Fig. 1. Principal component analysis (PCA) for the DNA methylation levels of the samples PCA was performed using the full microarray data from patients (blue points) and controls (red points) and showed two independent clusters.

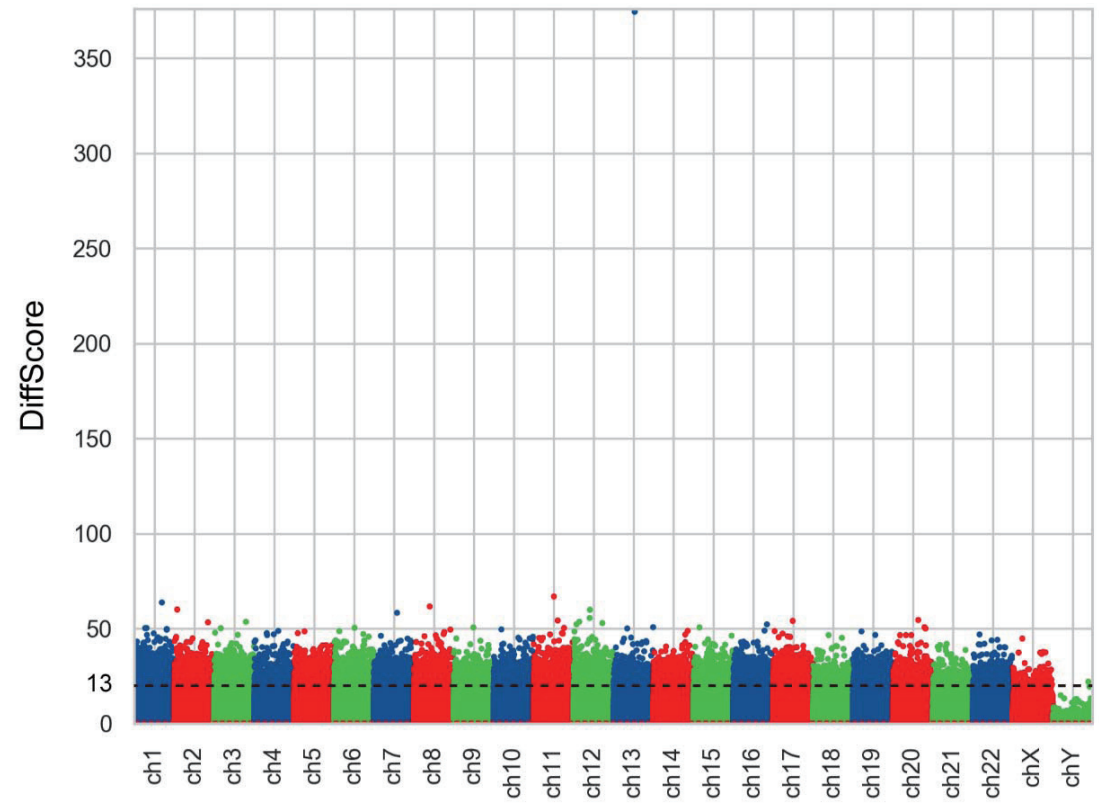

Supplementary Fig.2. Manhattan plots showing distribution of possible differentially methylated CpG sites identified in this study across chromosomes

The black dotted horizontal line indicates the genome-wide significance threshold of an absolute value of DiffScore $>13$. 
Supplementary Table 1. Baseline and clinical characteristics of the participants for pyrosequencing

\begin{tabular}{|c|c|c|c|}
\hline Characteristic & $\begin{array}{l}\text { Patients } \\
(n=21)\end{array}$ & $\begin{array}{c}\text { Controls } \\
(n=21)\end{array}$ & $P$ value \\
\hline \multicolumn{4}{|l|}{ Demographics } \\
\hline Age (years) & $55(48,59)$ & $57(53,59)$ & 0.732 \\
\hline Male (\%) & $19(90.5)$ & $19(90.5)$ & 1.000 \\
\hline Hypertension (\%) & $17(81.0)$ & $12(57.1)$ & 0.181 \\
\hline Diabetes mellitus (\%) & $8(38.1)$ & $8(38.1)$ & 1.000 \\
\hline Dyslipidaemia (\%) & $14(66.7)$ & $10(47.6)$ & 0.350 \\
\hline Smoking (\%) & $15(71.4)$ & $14(66.7)$ & 1.000 \\
\hline Drinking (\%) & $8(38.1)$ & $8(38.1)$ & 1.000 \\
\hline $\mathrm{SBP}(\mathrm{mmHg})$ & $148.1 \pm 19.6$ & $144.0 \pm 28.0$ & 0.585 \\
\hline $\mathrm{DBP}(\mathrm{mmHg})$ & $80.8 \pm 10.0$ & $86.9 \pm 28.0$ & 0.164 \\
\hline \multicolumn{4}{|l|}{ Laboratory parameters } \\
\hline $\mathrm{FBG}(\mathrm{mmol} / \mathrm{L})$ & $5.85(5.05,6.95)$ & $5.85(5.53,6.35)$ & 0.886 \\
\hline $\mathrm{TG}(\mathrm{mmol} / \mathrm{L})$ & $1.85(1.22,2.09)$ & $1.73(1.12,2.48)$ & 0.940 \\
\hline $\mathrm{TC}(\mathrm{mmol} / \mathrm{L})$ & $3.85(3.45,4.87)$ & $3.80(3.41,4.08)$ & 0.725 \\
\hline HDL-C (mmol/L) & $0.87 \pm 0.19$ & $0.91 \pm 0.25$ & 0.550 \\
\hline LDL-C (mmol/L) & $2.79 \pm 1.00$ & $2.58 \pm 0.98$ & 0.504 \\
\hline Homocysteine $(\mu \mathrm{mol} / \mathrm{L})$ & $15.60(11.20,27.30)$ & $13.00(10.93,17.38)$ & 0.210 \\
\hline Fibrinogen $(\mathrm{g} / \mathrm{L})$ & $2.47(2.04,2.97)$ & $2.37(2.07,2.60)$ & 0.355 \\
\hline CRP (mg/L) & $3.39(3.09,6.50)$ & $3.30(3.02,3.74)$ & 0.402 \\
\hline Urea nitrogen $(\mathrm{mmol} / \mathrm{L})$ & $5.00(4.18,6.48)$ & $5.00(3.88,6.25)$ & 0.507 \\
\hline Uric acid $(\mu \mathrm{mol} / \mathrm{L})$ & $282.67 \pm 78.60$ & $316.68 \pm 77.62$ & 0.177 \\
\hline Creatinine $(\mu \mathrm{mol} / \mathrm{L})$ & $85.00(74.50,96.75)$ & $86.50(78.00,96.25)$ & 0.979 \\
\hline
\end{tabular}

Continuous variables are expressed as the mean \pm standard deviation or the median (interquartile range). Categorical values are presented as frequencies (percentages).

Abbreviations: SBP, systolic blood pressure; DBP, diastolic blood pressure; FBG, fasting blood glucose; TG, triglycerides; TC, total cholesterol; HDL-C, high-density lipoprotein cholesterol; LDL-C, low-density lipoprotein cholesterol; CRP, C-reactive protein. 
Supplementary Table 2. Differentially methylated CpG sites between patients and controls. Single CpG with an absolute value of Diffscore $>13$ and an absolute value of Delta_Beta $>0.17$ were considered as differentially methylated loci

\begin{tabular}{|c|c|c|c|c|c|c|c|c|}
\hline $\begin{array}{l}\text { Serial } \\
\text { number }\end{array}$ & CpG site ID & $\begin{array}{l}\text { Chromo } \\
\text { some }\end{array}$ & Position & UCSC_RefGene_Name & $\begin{array}{l}\text { AVG_Beta } \\
\text { in patients }\end{array}$ & $\begin{array}{l}\text { AVG_Beta } \\
\text { in controls }\end{array}$ & Delta Beta & DiffScore \\
\hline 1 & $\operatorname{cg} 08977311$ & 3 & 168308798 & C3orf50 & 0.293 & 0.790 & -0.497 & -22.578 \\
\hline 2 & cg26263138 & $\mathrm{X}$ & 47633928 & & 0.172 & 0.650 & -0.478 & -23.065 \\
\hline 3 & $\operatorname{cg} 17348244$ & 7 & 786861 & HEATR2 & 0.173 & 0.630 & -0.457 & -15.396 \\
\hline 4 & $\operatorname{cg} 16661266$ & 13 & 31819391 & B3GLCT & 0.307 & 0.759 & -0.452 & -14.175 \\
\hline 5 & $\operatorname{cg} 08522473$ & 3 & 111730545 & TAGLN3; TAGLN3; TAGLN3 & 0.287 & 0.727 & -0.440 & -18.498 \\
\hline 6 & $\operatorname{cg} 03749159$ & 8 & 133714769 & & 0.361 & 0.793 & -0.433 & -18.496 \\
\hline 7 & $\operatorname{cg} 10123377$ & 3 & 42387524 & & 0.312 & 0.717 & -0.405 & -22.520 \\
\hline 8 & $\operatorname{cg} 13239126$ & 1 & 15256136 & $\begin{array}{l}\text { KIAA1026; KIAA1026; KIAA1026; } \\
\text { KIAA1026 }\end{array}$ & 0.359 & 0.757 & -0.397 & -18.024 \\
\hline 9 & cg21838924 & 7 & 73245103 & CLDN4 & 0.405 & 0.801 & -0.396 & -18.998 \\
\hline 10 & $\operatorname{cg} 10930703$ & 18 & 43570033 & PSTPIP2 & 0.452 & 0.840 & -0.388 & -17.581 \\
\hline 11 & cg24398793 & 7 & 15651770 & MEOX2 & 0.227 & 0.613 & -0.386 & -17.868 \\
\hline 12 & $\operatorname{cg} 21741515$ & 3 & 196048411 & & 0.269 & 0.651 & -0.383 & -14.615 \\
\hline 13 & $\operatorname{cg} 21714731$ & 3 & 79701155 & ROBO1 & 0.215 & 0.597 & -0.381 & -19.551 \\
\hline 14 & $\operatorname{cg} 02866897$ & 20 & 37470452 & PPP1R16B; PPP1R16B & 0.210 & 0.582 & -0.372 & -15.444 \\
\hline 15 & $\operatorname{cg} 03136151$ & 1 & 92415048 & BRDT; BRDT & 0.465 & 0.835 & -0.369 & -18.434 \\
\hline 16 & $\operatorname{cg} 16037139$ & 6 & 47040730 & & 0.465 & 0.833 & -0.368 & -16.434 \\
\hline 17 & cg00814186 & 17 & 74585455 & & 0.254 & 0.616 & -0.363 & -17.294 \\
\hline 18 & cg04307318 & 6 & 56244487 & RNU6-71P & 0.217 & 0.577 & -0.360 & -13.060 \\
\hline 19 & cg26588921 & 1 & 40183922 & & 0.227 & 0.587 & -0.360 & -23.434 \\
\hline 20 & cg05192017 & 12 & 115273077 & & 0.085 & 0.439 & -0.354 & -25.129 \\
\hline 21 & $\operatorname{cg} 10765459$ & 21 & 47524956 & COL6A2; COL6A2; COL6A2 & 0.391 & 0.744 & -0.353 & -14.405 \\
\hline 22 & $\operatorname{cg} 03221390$ & 1 & 247803637 & & 0.091 & 0.440 & -0.349 & -23.252 \\
\hline 23 & $\operatorname{cg} 16310958$ & 20 & 25281332 & ABHD12; ABHD12 & 0.089 & 0.433 & -0.344 & -13.666 \\
\hline 24 & $\operatorname{cg} 21415084$ & 12 & 84218134 & & 0.400 & 0.741 & -0.341 & -16.413 \\
\hline 25 & cg21130926 & 20 & 46415320 & SULF2; SULF2; SULF2; SULF2; SULF2 & 0.485 & 0.820 & -0.335 & -15.902 \\
\hline 26 & $\operatorname{cg} 13920856$ & 2 & 159867184 & TANC1; TANC1 & 0.352 & 0.680 & -0.327 & -16.415 \\
\hline 27 & $\operatorname{cg} 15441831$ & 7 & 73245178 & CLDN4 & 0.447 & 0.772 & -0.325 & -17.383 \\
\hline 28 & $\operatorname{cg} 11282840$ & 8 & 49057154 & & 0.486 & 0.810 & -0.324 & -35.283 \\
\hline 29 & $\operatorname{cg} 18444757$ & 18 & 12035841 & & 0.085 & 0.408 & -0.323 & -13.591 \\
\hline 30 & $\operatorname{cg} 01359658$ & 7 & 2426868 & & 0.421 & 0.743 & -0.322 & -13.715 \\
\hline 32 & $\operatorname{cg} 11016221$ & 9 & 132505647 & PTGES & 0.472 & 0.783 & -0.311 & -24.572 \\
\hline 33 & cg07227024 & 2 & 202163482 & ALS2CR12; ALS2CR12 & 0.221 & 0.529 & -0.308 & -19.581 \\
\hline 34 & cg24329141 & 10 & 27095369 & ABI1; ABI1; ABI1; ABI1 & 0.608 & 0.915 & -0.307 & -40.978 \\
\hline 35 & $\operatorname{cg} 00740510$ & 22 & 43811071 & MPPED1 & 0.184 & 0.489 & -0.306 & -14.400 \\
\hline 36 & $\operatorname{cg} 06995503$ & 10 & 3178915 & PFKP & 0.585 & 0.888 & -0.302 & -27.762 \\
\hline 37 & cg02794920 & 3 & 23243300 & UBE2E2 & 0.498 & 0.797 & -0.298 & -13.903 \\
\hline 38 & $\operatorname{cg} 16935517$ & 10 & 11577115 & USP6NL & 0.446 & 0.738 & -0.292 & -15.934 \\
\hline 39 & cg04998153 & 1 & 101823331 & LINC01307 & 0.310 & 0.600 & -0.290 & -19.385 \\
\hline 40 & $\operatorname{cg} 22786333$ & 7 & 801211 & HEATR2 & 0.358 & 0.643 & -0.285 & -15.330 \\
\hline 41 & $\operatorname{cg} 07469467$ & 12 & 99092857 & APAF1; APAF1; APAF1; APAF1; APAF1 & 0.077 & 0.360 & -0.284 & -22.648 \\
\hline 42 & cg07895205 & 1 & 94240679 & BCAR3 & 0.431 & 0.715 & -0.283 & -18.465 \\
\hline 43 & $\operatorname{cg} 11173636$ & 10 & 65632259 & & 0.051 & 0.333 & -0.283 & -17.786 \\
\hline 44 & cg02730303 & 11 & 103480630 & & 0.032 & 0.311 & -0.279 & -26.937 \\
\hline 45 & cg03639185 & 4 & 144207789 & & 0.021 & 0.293 & -0.272 & -18.310 \\
\hline 46 & cg00570635 & 2 & 65355269 & RAB1A; RAB1A & 0.093 & 0.363 & -0.270 & -23.122 \\
\hline 47 & $\operatorname{cg} 12052601$ & 2 & 100900379 & LONRF2 & 0.253 & 0.522 & -0.268 & -13.884 \\
\hline 48 & cg27281836 & 11 & 49229833 & FOLH1; FOLH1 & 0.065 & 0.332 & -0.267 & -13.357 \\
\hline 49 & cg24022528 & 7 & 140393175 & ADCK2 & 0.629 & 0.894 & -0.266 & -25.146 \\
\hline
\end{tabular}


(Cont. Supplementary Table 2)

\begin{tabular}{|c|c|c|c|c|c|c|c|c|}
\hline $\begin{array}{l}\text { Serial } \\
\text { number }\end{array}$ & CpG site ID & $\begin{array}{l}\text { Chromo } \\
\text { some }\end{array}$ & Position & UCSC_RefGene_Name & $\begin{array}{l}\text { AVG_Beta } \\
\text { in patients }\end{array}$ & $\begin{array}{l}\text { AVG_Beta } \\
\text { in controls }\end{array}$ & Delta Beta & DiffScore \\
\hline 50 & $\operatorname{cg} 08238375$ & 5 & 112483149 & MCC; MCC & 0.334 & 0.597 & -0.263 & -13.575 \\
\hline 51 & $\operatorname{cg} 19288863$ & 6 & 133749548 & EYA4; EYA4; EYA4; EYA4; EYA4 & 0.606 & 0.869 & -0.263 & -13.607 \\
\hline 52 & $\operatorname{cg} 25249362$ & 10 & 3163518 & PFKP & 0.644 & 0.902 & -0.258 & -17.129 \\
\hline 53 & $\operatorname{cg} 05182217$ & 7 & 138803256 & & 0.381 & 0.637 & -0.256 & -16.720 \\
\hline 54 & $\operatorname{cg} 00173776$ & 1 & 31465032 & PUM1; PUM1 & 0.569 & 0.822 & -0.253 & -17.894 \\
\hline 55 & $\operatorname{cg} 25771369$ & 14 & 20528494 & OR4L1 & 0.355 & 0.607 & -0.252 & -17.825 \\
\hline 56 & $\operatorname{cg} 16145187$ & 17 & 53684393 & & 0.466 & 0.713 & -0.247 & -17.811 \\
\hline 57 & $\operatorname{cg} 00113675$ & 6 & 29855347 & HLA-H & 0.221 & 0.467 & -0.246 & -14.165 \\
\hline 58 & $\operatorname{cg} 26889118$ & 15 & 49342629 & & 0.394 & 0.640 & -0.246 & -13.043 \\
\hline 59 & $\operatorname{cg} 10993865$ & 13 & 111293846 & CARS2 & 0.659 & 0.898 & -0.239 & -17.714 \\
\hline 60 & cg09258259 & 19 & 3143043 & $\begin{array}{l}\text { LOC100996351; GNA15; } \\
\text { LOC100996351 }\end{array}$ & 0.086 & 0.325 & -0.239 & -24.665 \\
\hline 61 & $\operatorname{cg} 01354003$ & 8 & 6422103 & $\begin{array}{l}\text { ANGPT2; ANGPT2; ANGPT2; } \\
\text { MCPH1 }\end{array}$ & 0.130 & 0.368 & -0.238 & -18.462 \\
\hline 62 & $\operatorname{cg} 12589297$ & 15 & 67136155 & & 0.292 & 0.529 & -0.238 & -17.323 \\
\hline 63 & cg23329272 & 5 & 180085924 & & 0.171 & 0.407 & -0.236 & -26.200 \\
\hline 64 & $\operatorname{cg} 10288111$ & 7 & 112062682 & IFRD1 & 0.324 & 0.556 & -0.232 & -18.503 \\
\hline 65 & cg21932934 & 11 & 120039306 & & 0.553 & 0.785 & -0.232 & -20.501 \\
\hline 66 & $\operatorname{cg} 07138269$ & 8 & 72765107 & MSC-AS1; MSC-AS1 & 0.597 & 0.828 & -0.231 & -14.165 \\
\hline 67 & $\operatorname{cg} 07056794$ & 9 & 139318309 & & 0.616 & 0.847 & -0.231 & -16.710 \\
\hline 68 & $\operatorname{cg} 16033700$ & 4 & 14868419 & LINC00504 & 0.558 & 0.789 & -0.231 & -16.236 \\
\hline 69 & $\operatorname{cg} 25576961$ & 15 & 99709980 & $\begin{array}{l}\text { TTC23; TTC23; TTC23; ТTC23; } \\
\text { TTC23; TTC23; ТTC23 }\end{array}$ & 0.538 & 0.769 & -0.231 & -13.767 \\
\hline 70 & $\operatorname{cg} 05407981$ & 2 & 202289316 & TRAK2 & 0.523 & 0.749 & -0.225 & -13.664 \\
\hline 71 & $\operatorname{cg} 12063064$ & 3 & 48712367 & NCKIPSD; NCKIPSD & 0.656 & 0.881 & -0.225 & -16.775 \\
\hline 72 & $\operatorname{cg} 07044859$ & 10 & 101282883 & & 0.165 & 0.390 & -0.225 & -13.591 \\
\hline 73 & $\operatorname{cg} 09281805$ & 7 & 4751840 & FOXK1 & 0.639 & 0.863 & -0.224 & -19.263 \\
\hline 74 & $\operatorname{cg} 18352080$ & 1 & 2004953 & PRKCZ; PRKCZ; PRKCZ & 0.645 & 0.868 & -0.223 & -17.388 \\
\hline 75 & $\operatorname{cg} 24795173$ & 10 & 108751940 & $\begin{array}{l}\text { SORCS1; SORCS1; SORCS1; SORCS1; } \\
\text { SORCS1; SORCS1 }\end{array}$ & 0.353 & 0.575 & -0.223 & -20.450 \\
\hline 76 & $\operatorname{cg} 23230564$ & 5 & 31470890 & RNASEN; RNASEN & 0.282 & 0.503 & -0.221 & -17.710 \\
\hline 77 & $\operatorname{cg} 18805164$ & 19 & 36265700 & SNX26 & 0.691 & 0.909 & -0.218 & -15.024 \\
\hline 78 & $\operatorname{cg} 03964373$ & 1 & 241800323 & CHML; OPN3 & 0.659 & 0.877 & -0.218 & -23.684 \\
\hline 79 & $\operatorname{cg} 02631626$ & 13 & 27546802 & & 0.384 & 0.600 & -0.216 & -17.758 \\
\hline 80 & $\operatorname{cg} 04610742$ & 1 & 230513809 & PGBD5 & 0.474 & 0.688 & -0.214 & -15.276 \\
\hline 81 & $\operatorname{cg} 06075754$ & 10 & 104169733 & PSD & 0.455 & 0.668 & -0.213 & -13.315 \\
\hline 82 & $\operatorname{cg} 02953125$ & 2 & 1079100 & SNTG2 & 0.632 & 0.845 & -0.213 & -16.972 \\
\hline 83 & $\operatorname{cg} 03971505$ & 12 & 22063949 & ABCC9; ABCC9 & 0.164 & 0.373 & -0.209 & -21.683 \\
\hline 84 & $\operatorname{cg} 05990366$ & 12 & 124773693 & FAM101A & 0.657 & 0.866 & -0.209 & -17.168 \\
\hline 85 & $\operatorname{cg} 13110951$ & 1 & 246746101 & CNST; CNST & 0.372 & 0.579 & -0.208 & -16.599 \\
\hline 86 & $\operatorname{cg} 16749629$ & 12 & 66459807 & & 0.370 & 0.577 & -0.207 & -23.075 \\
\hline 87 & $\operatorname{cg} 14144366$ & 10 & 61764026 & & 0.562 & 0.766 & -0.204 & -14.448 \\
\hline 88 & $\operatorname{cg} 14773207$ & 18 & 43567084 & PSTPIP2 & 0.542 & 0.743 & -0.201 & -16.466 \\
\hline 89 & $\operatorname{cg} 02662417$ & 6 & 157161545 & ARID1B; ARID1B; ARID1B & 0.555 & 0.753 & -0.198 & -27.851 \\
\hline 90 & $\operatorname{cg} 17888390$ & 10 & 101282816 & & 0.135 & 0.333 & -0.198 & -14.137 \\
\hline 91 & $\operatorname{cg} 11233593$ & 4 & 83955464 & COPS4; COPS4 & 0.124 & 0.319 & -0.195 & -27.901 \\
\hline 92 & $\operatorname{cg} 13363575$ & 2 & 131967322 & & 0.389 & 0.584 & -0.195 & -15.852 \\
\hline 93 & $\operatorname{cg} 18399194$ & 10 & 101918448 & ERLIN1; ERLIN1 & 0.682 & 0.875 & -0.193 & -20.530 \\
\hline 94 & $\operatorname{cg} 09235562$ & 19 & 384251 & & 0.500 & 0.691 & -0.192 & -29.468 \\
\hline 95 & $\operatorname{cg} 13462557$ & 1 & 62499140 & INADL & 0.661 & 0.851 & -0.190 & -14.527 \\
\hline 96 & $\operatorname{cg} 12460140$ & 12 & 77771462 & & 0.421 & 0.611 & -0.190 & -13.579 \\
\hline
\end{tabular}


(Cont. Supplementary Table 2)

\begin{tabular}{|c|c|c|c|c|c|c|c|c|}
\hline $\begin{array}{l}\text { Serial } \\
\text { number }\end{array}$ & CpG site ID & $\begin{array}{l}\text { Chromo } \\
\text { some }\end{array}$ & Position & UCSC_RefGene_Name & $\begin{array}{l}\text { AVG_Beta } \\
\text { in patients }\end{array}$ & $\begin{array}{l}\text { AVG_Beta } \\
\text { in controls }\end{array}$ & Delta Beta & DiffScore \\
\hline 97 & $\operatorname{cg} 17789193$ & 19 & 14533491 & & 0.199 & 0.387 & -0.189 & -25.666 \\
\hline 98 & $\operatorname{cg} 03185552$ & 17 & 81060259 & & 0.522 & 0.711 & -0.189 & -14.037 \\
\hline 99 & $\operatorname{cg} 07590402$ & 10 & 104840433 & & 0.636 & 0.824 & -0.188 & -16.039 \\
\hline 100 & $\operatorname{cg} 23221052$ & 5 & 179740743 & GFPT2 & 0.438 & 0.626 & -0.188 & -15.892 \\
\hline 101 & $\operatorname{cg} 26930243$ & 3 & 117482571 & & 0.311 & 0.499 & -0.188 & -16.534 \\
\hline 102 & $\operatorname{cg} 24391912$ & 15 & 100259320 & & 0.124 & 0.312 & -0.188 & -14.732 \\
\hline 103 & $\operatorname{cg} 12824232$ & 1 & 101842425 & LINC01307 & 0.706 & 0.891 & -0.185 & -15.229 \\
\hline 104 & $\operatorname{cg} 17113546$ & 12 & 10451780 & & 0.680 & 0.865 & -0.185 & -16.559 \\
\hline 105 & $\operatorname{cg} 10001720$ & 1 & 31231363 & LAPTM5 & 0.449 & 0.634 & -0.185 & -18.501 \\
\hline 106 & $\operatorname{cg} 06074563$ & $\mathrm{X}$ & 107980779 & LOC101928358; IRS4 & 0.198 & 0.382 & -0.185 & -15.015 \\
\hline 107 & $\operatorname{cg} 23540632$ & 18 & 67253448 & DOK6 & 0.482 & 0.666 & -0.184 & -25.384 \\
\hline 108 & $\operatorname{cg} 05850769$ & 14 & 88470085 & GPR65 & 0.284 & 0.468 & -0.184 & -15.075 \\
\hline 109 & $\operatorname{cg} 00366603$ & 6 & 32186049 & NOTCH4 & 0.650 & 0.834 & -0.184 & -14.923 \\
\hline 110 & $\operatorname{cg} 22188184$ & 6 & 101168404 & ASCC3; ASCC3 & 0.202 & 0.386 & -0.183 & -18.138 \\
\hline 111 & $\operatorname{cg} 16706502$ & 14 & 31927974 & C14orf126 & 0.328 & 0.511 & -0.183 & -14.920 \\
\hline 112 & $\operatorname{cg} 03853124$ & 6 & 33875958 & & 0.229 & 0.412 & -0.183 & -40.741 \\
\hline 113 & cg00495303 & 18 & 3771110 & DLGAP1; DLGAP1 & 0.393 & 0.575 & -0.182 & -13.231 \\
\hline 114 & cg21743623 & 3 & 130682976 & ATP2C1; АTP2C1; ATP2C1; ATP2C1 & 0.284 & 0.465 & -0.181 & -14.772 \\
\hline 115 & $\operatorname{cg} 19707454$ & 7 & 6616677 & $\begin{array}{l}\text { ZDHHC4; ZDHHC4; ZDHHC4; } \\
\text { ZDHHC4 }\end{array}$ & 0.538 & 0.718 & -0.180 & -14.951 \\
\hline 116 & $\operatorname{cg} 04345661$ & 20 & 32721338 & & 0.382 & 0.562 & -0.180 & -23.844 \\
\hline 117 & $\operatorname{cg} 10356706$ & 6 & 167639159 & & 0.238 & 0.417 & -0.179 & -15.332 \\
\hline 118 & $\operatorname{cg} 01501399$ & 13 & 27557211 & & 0.277 & 0.456 & -0.179 & -25.786 \\
\hline 119 & $\operatorname{cg} 06304546$ & 20 & 32448765 & & 0.550 & 0.728 & -0.178 & -18.794 \\
\hline 120 & $\operatorname{cg} 16201634$ & 1 & 9146357 & & 0.446 & 0.623 & -0.178 & -27.955 \\
\hline 121 & $\operatorname{cg} 19224645$ & 1 & 39282003 & & 0.123 & 0.300 & -0.177 & -24.401 \\
\hline 122 & $\operatorname{cg} 06715136$ & 7 & 158046025 & PTPRN2; PTPRN2; PTPRN2 & 0.686 & 0.862 & -0.176 & -16.955 \\
\hline 123 & $\operatorname{cg} 17764313$ & 3 & 127335263 & MCM2; MCM2 & 0.612 & 0.787 & -0.175 & -15.379 \\
\hline 124 & $\operatorname{cg} 14087524$ & 1 & 38349487 & INPP5B; INPP5B & 0.431 & 0.605 & -0.174 & -14.982 \\
\hline 125 & $\operatorname{cg} 08584759$ & 10 & 11912126 & C10orf47 & 0.654 & 0.828 & -0.174 & -15.768 \\
\hline 126 & $\operatorname{cg} 06835411$ & 4 & 186301987 & & 0.630 & 0.803 & -0.174 & -14.912 \\
\hline 127 & $\operatorname{cg} 00553601$ & 1 & 224268136 & & 0.642 & 0.815 & -0.174 & -13.757 \\
\hline 128 & $\operatorname{cg} 20916362$ & 3 & 39821326 & & 0.625 & 0.798 & -0.173 & -15.895 \\
\hline 129 & $\operatorname{cg} 26749518$ & 19 & 51506165 & KLK9; KLK8; KLK8; KLK8; KLK8 & 0.376 & 0.549 & -0.173 & -18.916 \\
\hline 130 & $\operatorname{cg} 01438711$ & 17 & 69789307 & & 0.081 & 0.253 & -0.172 & -15.951 \\
\hline 131 & $\operatorname{cg} 20720056$ & 10 & 101910498 & ERLIN1; ERLIN1 & 0.727 & 0.899 & -0.172 & -19.068 \\
\hline 132 & $\operatorname{cg} 06637768$ & 6 & 2886816 & LOC101927730 & 0.079 & 0.250 & -0.172 & -16.451 \\
\hline 133 & $\operatorname{cg} 14361804$ & 9 & 117694183 & TNFSF8 & 0.354 & 0.525 & -0.172 & -13.152 \\
\hline 134 & $\operatorname{cg} 19935450$ & 10 & 6281135 & & 0.488 & 0.659 & -0.171 & -21.693 \\
\hline 135 & $\operatorname{cg} 13837146$ & 9 & 111548749 & & 0.373 & 0.543 & -0.170 & -19.836 \\
\hline 136 & $\operatorname{cg} 01429604$ & 12 & 95264769 & & 0.733 & 0.563 & 0.170 & 14.178 \\
\hline 137 & $\operatorname{cg} 23100626$ & 2 & 96804247 & ASTL & 0.699 & 0.527 & 0.171 & 16.154 \\
\hline 138 & $\operatorname{cg} 24578857$ & 17 & 17110207 & PLD6 & 0.724 & 0.552 & 0.171 & 45.426 \\
\hline 139 & $\operatorname{cg} 13799572$ & 11 & 126382235 & KIRREL3; KIRREL3; KIRREL3 & 0.850 & 0.678 & 0.173 & 13.887 \\
\hline 140 & $\operatorname{cg} 12790145$ & 12 & 312737 & $\begin{array}{l}\text { LOC101929384; SLC6A12; SLC6A12; } \\
\text { SLC6A12; SLC6A12 }\end{array}$ & 0.586 & 0.412 & 0.174 & 15.535 \\
\hline 141 & cg21862353 & 2 & 1801628 & MYT1L & 0.730 & 0.556 & 0.174 & 15.696 \\
\hline 142 & cg14112997 & 22 & 17591088 & IL17RA & 0.559 & 0.384 & 0.175 & -18.176 \\
\hline 143 & $\operatorname{cg} 14651079$ & 10 & 88428177 & $\begin{array}{l}\text { LDB3; LDB3; LDB3; LDB3; LDB3; } \\
\text { LDB3 }\end{array}$ & 0.839 & 0.664 & 0.175 & 17.571 \\
\hline
\end{tabular}


(Cont. Supplementary Table 2)

\begin{tabular}{|c|c|c|c|c|c|c|c|c|}
\hline $\begin{array}{l}\text { Serial } \\
\text { number }\end{array}$ & CpG site ID & $\begin{array}{l}\text { Chromo } \\
\text { some }\end{array}$ & Position & UCSC_RefGene_Name & $\begin{array}{l}\text { AVG_Beta } \\
\text { in patients }\end{array}$ & $\begin{array}{l}\text { AVG_Beta } \\
\text { in controls }\end{array}$ & Delta Beta & DiffScore \\
\hline 144 & $\operatorname{cg} 02295574$ & 5 & 1054262 & SLC12A7 & 0.863 & 0.686 & 0.176 & 14.505 \\
\hline 145 & $\operatorname{cg} 26337497$ & 3 & 31935279 & OSBPL10 & 0.524 & 0.347 & 0.177 & 15.288 \\
\hline 146 & $\operatorname{cg} 16222062$ & 14 & 105509229 & & 0.948 & 0.770 & 0.178 & 32.118 \\
\hline 147 & $\operatorname{cg} 07743747$ & 3 & 46394550 & CCR2; CCR2 & 0.514 & 0.336 & 0.178 & 14.127 \\
\hline 148 & $\operatorname{cg} 05635359$ & 8 & 39272909 & & 0.548 & 0.370 & 0.178 & 21.267 \\
\hline 149 & $\operatorname{cg} 00950476$ & 12 & 11708930 & LINC01252 & 0.497 & 0.319 & 0.179 & 17.296 \\
\hline 150 & $\operatorname{cg} 19537558$ & 5 & 167550996 & ODZ2 & 0.848 & 0.669 & 0.180 & 14.696 \\
\hline 151 & $\operatorname{cg} 11890239$ & 8 & 103541014 & & 0.512 & 0.333 & 0.180 & 19.714 \\
\hline 152 & $\operatorname{cg} 08713344$ & 10 & 3183772 & $\begin{array}{l}\text { PITRM1-AS1; PITRM1; PITRM1; } \\
\text { PITRM1 }\end{array}$ & 0.794 & 0.613 & 0.181 & 19.593 \\
\hline 153 & $\operatorname{cg} 11403739$ & 15 & 22923741 & CYFIP1 & 0.563 & 0.382 & 0.181 & 13.247 \\
\hline 154 & cg24496423 & $\mathrm{X}$ & 153046480 & $\begin{array}{l}\text { SRPK3; SRPK3; SRPK3; SRPK3; } \\
\text { SRPK3; SRPK3 }\end{array}$ & 0.503 & 0.322 & 0.181 & 20.845 \\
\hline 155 & $\operatorname{cg} 06001976$ & $\mathrm{X}$ & 3790470 & & 0.721 & 0.540 & 0.181 & 17.999 \\
\hline 156 & cg20360416 & 4 & 7246127 & SORCS2 & 0.869 & 0.688 & 0.181 & 15.131 \\
\hline 157 & $\operatorname{cg} 05531409$ & 3 & 131637172 & CPNE4 & 0.802 & 0.620 & 0.181 & 15.419 \\
\hline 158 & $\operatorname{cg} 27266060$ & 8 & 22091797 & & 0.608 & 0.427 & 0.181 & 15.051 \\
\hline 159 & $\operatorname{cg} 00525277$ & 6 & 32064239 & TNXB & 0.653 & 0.470 & 0.184 & 35.837 \\
\hline 160 & $\operatorname{cg} 16655091$ & 13 & 26590097 & ATP8A2 & 0.853 & 0.667 & 0.185 & 18.585 \\
\hline 161 & cg20964965 & 10 & 134564563 & INPP5A & 0.888 & 0.703 & 0.186 & 13.066 \\
\hline 162 & $\operatorname{cg} 16645815$ & 10 & 134556992 & INPP5A & 0.924 & 0.738 & 0.186 & 13.850 \\
\hline 163 & $\operatorname{cg} 07639376$ & 16 & 1584516 & IFT140; TMEM204 & 0.564 & 0.378 & 0.186 & 13.393 \\
\hline 164 & $\operatorname{cg} 10890302$ & 6 & 32064246 & TNXB & 0.442 & 0.255 & 0.187 & 27.733 \\
\hline 165 & $\operatorname{cg} 07524919$ & 6 & 32063901 & TNXB & 0.660 & 0.472 & 0.188 & 24.523 \\
\hline 166 & $\operatorname{cg} 19106932$ & 17 & 61926700 & & 0.418 & 0.230 & 0.188 & 18.804 \\
\hline 167 & $\operatorname{cg} 15265085$ & 6 & 32064588 & TNXB & 0.459 & 0.271 & 0.189 & 16.969 \\
\hline 168 & $\operatorname{cg} 27625131$ & 13 & 113105794 & & 0.781 & 0.593 & 0.189 & 23.813 \\
\hline 169 & $\operatorname{cg} 14096311$ & 4 & 152117184 & SH3D19; SH3D19; SH3D19 & 0.457 & 0.267 & 0.190 & 13.469 \\
\hline 170 & $\operatorname{cg} 09087222$ & 8 & 11720363 & CTSB; CTSB; CTSB; CTSB; CTSB & 0.588 & 0.398 & 0.190 & 29.006 \\
\hline 171 & $\operatorname{cg} 26094651$ & 2 & 1802045 & MYT1L & 0.762 & 0.572 & 0.190 & 13.569 \\
\hline 172 & $\operatorname{cg} 10510935$ & 1 & 4059661 & & 0.498 & 0.307 & 0.191 & 14.195 \\
\hline 173 & $\operatorname{cg} 15196197$ & 6 & 32064573 & TNXB & 0.300 & 0.107 & 0.192 & 19.530 \\
\hline 174 & $\operatorname{cg} 25218220$ & 13 & 46895635 & & 0.583 & 0.391 & 0.192 & 32.598 \\
\hline 175 & $\operatorname{cg} 06892295$ & 10 & 84158395 & NRG3; NRG3; NRG3 & 0.837 & 0.644 & 0.193 & 13.130 \\
\hline 176 & $\operatorname{cg} 00079566$ & 3 & 177194742 & LINC00578 & 0.848 & 0.651 & 0.198 & 14.518 \\
\hline 177 & $\operatorname{cg} 27387193$ & 6 & 32064032 & TNXB & 0.598 & 0.400 & 0.198 & 35.411 \\
\hline 178 & $\operatorname{cg} 17253931$ & 8 & 127448577 & & 0.887 & 0.688 & 0.200 & 19.229 \\
\hline 179 & $\operatorname{cg} 22443212$ & 17 & 78253912 & RNF213; RNF213 & 0.719 & 0.518 & 0.201 & 18.659 \\
\hline 180 & $\operatorname{cg} 06120313$ & 11 & 3174092 & OSBPL5; OSBPL5; OSBPL5 & 0.650 & 0.448 & 0.202 & 21.043 \\
\hline 181 & $\operatorname{cg} 17608381$ & 6 & 29911550 & HLA-A & 0.683 & 0.480 & 0.203 & 21.019 \\
\hline 182 & $\operatorname{cg} 13914841$ & 16 & 75303457 & & 0.739 & 0.536 & 0.203 & 14.813 \\
\hline 183 & $\operatorname{cg} 10025714$ & 1 & 149150959 & & 0.629 & 0.425 & 0.204 & 18.853 \\
\hline 184 & $\operatorname{cg} 08880082$ & 14 & 90165664 & & 0.863 & 0.658 & 0.205 & 14.631 \\
\hline 185 & $\operatorname{cg} 23688827$ & 1 & 18767776 & & 0.843 & 0.637 & 0.205 & 15.325 \\
\hline 186 & cg12038518 & 11 & 128105129 & & 0.794 & 0.588 & 0.206 & 15.038 \\
\hline 187 & cg25533133 & 13 & 113664019 & MCF2L; MCF2L & 0.628 & 0.421 & 0.207 & 25.440 \\
\hline 188 & $\operatorname{cg} 05460746$ & 8 & 103541045 & & 0.362 & 0.155 & 0.207 & 32.908 \\
\hline 189 & $\operatorname{cg} 16834823$ & 6 & 32064218 & TNXB & 0.447 & 0.239 & 0.208 & 38.064 \\
\hline 190 & $\operatorname{cg} 13400512$ & 6 & 32064578 & TNXB & 0.382 & 0.173 & 0.209 & 21.644 \\
\hline 191 & $\operatorname{cg} 04175473$ & 10 & 134563870 & INPP5A & 0.901 & 0.691 & 0.210 & 15.328 \\
\hline
\end{tabular}


(Cont. Supplementary Table 2)

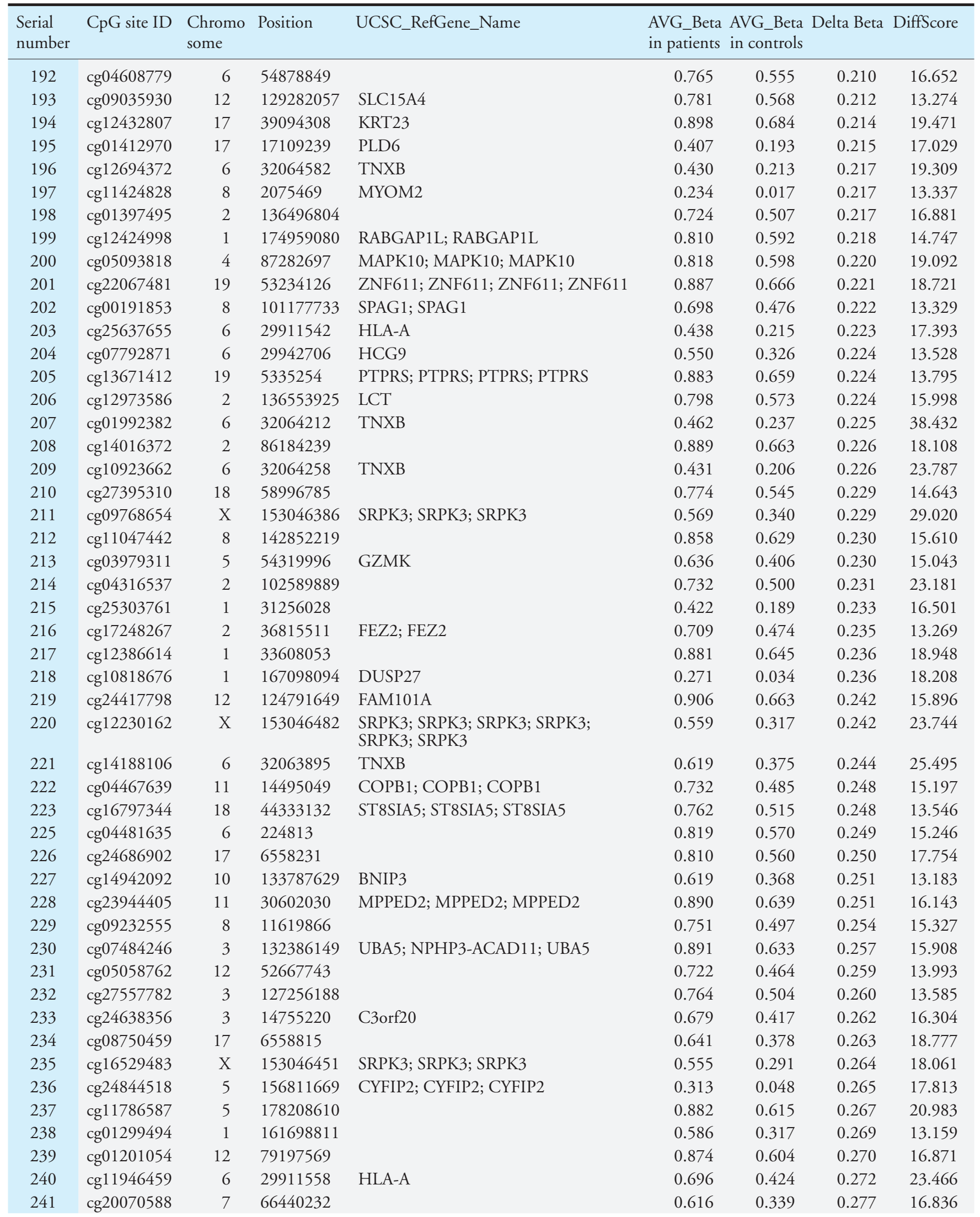


(Cont. Supplementary Table 2)

\begin{tabular}{|c|c|c|c|c|c|c|c|c|}
\hline $\begin{array}{l}\text { Serial } \\
\text { number }\end{array}$ & CpG site ID & $\begin{array}{l}\text { Chromo } \\
\text { some }\end{array}$ & Position & UCSC_RefGene_Name & $\begin{array}{l}\text { AVG_Beta } \\
\text { in patients }\end{array}$ & $\begin{array}{l}\text { AVG_Beta } \\
\text { in controls }\end{array}$ & Delta Beta & DiffScore \\
\hline 242 & cg20722168 & 4 & 38832495 & TLR6 & 0.831 & 0.553 & 0.279 & 13.068 \\
\hline 244 & $\operatorname{cg} 27160885$ & 15 & 74014211 & & 0.763 & 0.481 & 0.282 & 15.587 \\
\hline 245 & $\operatorname{cg} 03812172$ & 7 & 44184403 & GCK; GCK; GCK & 0.767 & 0.484 & 0.283 & 16.714 \\
\hline 246 & $\operatorname{cg} 15930509$ & 7 & 128078177 & & 0.837 & 0.554 & 0.283 & 13.256 \\
\hline 248 & $\operatorname{cg} 06653848$ & 11 & 109566635 & & 0.677 & 0.390 & 0.287 & 14.604 \\
\hline 249 & $\operatorname{cg} 06443038$ & 9 & 35904531 & & 0.735 & 0.448 & 0.287 & 21.037 \\
\hline 250 & $\operatorname{cg} 23168520$ & 13 & 114775133 & RASA3 & 0.788 & 0.501 & 0.287 & 15.942 \\
\hline 251 & $\operatorname{cg} 21358336$ & 17 & 6558440 & & 0.800 & 0.510 & 0.290 & 18.983 \\
\hline 252 & $\operatorname{cg} 07935157$ & 6 & 101403850 & & 0.746 & 0.456 & 0.290 & 14.625 \\
\hline 257 & $\operatorname{cg} 16044734$ & 17 & 41824694 & & 0.813 & 0.516 & 0.297 & 19.942 \\
\hline 258 & $\operatorname{cg} 21878369$ & 19 & 53194695 & ZNF83 & 0.417 & 0.117 & 0.299 & 27.587 \\
\hline 259 & $\operatorname{cg} 15290312$ & 17 & 76897139 & TIMP2 & 0.972 & 0.669 & 0.303 & 17.303 \\
\hline 260 & $\operatorname{cg} 05861138$ & 14 & 77376872 & & 0.848 & 0.544 & 0.304 & 14.207 \\
\hline 261 & $\operatorname{cg} 09022647$ & 8 & 39328883 & $\begin{array}{l}\text { ADAM3A; ADAM3A; ADAM3A; } \\
\text { ADAM3A }\end{array}$ & 0.768 & 0.461 & 0.308 & 17.477 \\
\hline 262 & $\operatorname{cg} 23390607$ & 11 & 74118907 & & 0.759 & 0.451 & 0.308 & 18.736 \\
\hline 263 & $\operatorname{cg} 19651115$ & 12 & 11700343 & & 0.766 & 0.455 & 0.312 & 18.107 \\
\hline 264 & $\operatorname{cg} 13885829$ & 1 & 17482041 & & 0.770 & 0.458 & 0.312 & 15.470 \\
\hline 265 & $\operatorname{cg} 04918505$ & $\mathrm{X}$ & 69716726 & DLG3; DLG3; DLG3 & 0.719 & 0.407 & 0.312 & 14.250 \\
\hline 273 & $\operatorname{cg} 16858433$ & 2 & 45383756 & & 0.892 & 0.563 & 0.329 & 13.031 \\
\hline 274 & $\operatorname{cg} 18105134$ & 13 & 113819100 & PROZ & 0.770 & 0.436 & 0.334 & 21.173 \\
\hline 275 & $\operatorname{cg} 13805962$ & 5 & 159391842 & ADRA1B & 0.905 & 0.570 & 0.335 & 19.461 \\
\hline 276 & $\operatorname{cg} 25259265$ & 13 & 114100875 & ADPRHL1; ADPRHL1 & 0.778 & 0.442 & 0.336 & 15.913 \\
\hline 277 & $\operatorname{cg} 15211026$ & 2 & 65639543 & SPRED2 & 0.846 & 0.510 & 0.336 & 15.578 \\
\hline 278 & $\operatorname{cg} 19084031$ & 15 & 38361362 & & 0.501 & 0.164 & 0.337 & 31.541 \\
\hline 279 & $\operatorname{cg} 10957001$ & 12 & 99118507 & APAF1; APAF1; APAF1; APAF1; APAF1 & 0.878 & 0.537 & 0.341 & 23.095 \\
\hline 280 & $\operatorname{cg} 04499455$ & 6 & 31356802 & & 0.652 & 0.311 & 0.341 & 14.858 \\
\hline 281 & $\operatorname{cg} 14889167$ & 5 & 132925337 & FSTL4 & 0.516 & 0.172 & 0.344 & 16.077 \\
\hline 282 & $\operatorname{cg} 27153751$ & 21 & 43869662 & & 0.688 & 0.344 & 0.344 & 15.652 \\
\hline 283 & $\operatorname{cg} 25641515$ & 12 & 132965879 & & 0.673 & 0.328 & 0.346 & 28.702 \\
\hline 284 & $\operatorname{cg} 08103988$ & 17 & 6558365 & & 0.828 & 0.481 & 0.347 & 18.111 \\
\hline 285 & $\operatorname{cg} 13117582$ & 17 & 81025461 & & 0.959 & 0.612 & 0.348 & 17.933 \\
\hline 286 & $\operatorname{cg} 01081438$ & 1 & 92417998 & BRDT; BRDT & 0.768 & 0.415 & 0.352 & 17.421 \\
\hline 287 & cg23893060 & 22 & 45498115 & & 0.834 & 0.478 & 0.356 & 15.586 \\
\hline 288 & $\operatorname{cg} 16917903$ & 18 & 722818 & YES1 & 0.870 & 0.512 & 0.359 & 13.794 \\
\hline 289 & $\operatorname{cg} 13905298$ & 5 & 141485167 & & 0.401 & 0.041 & 0.359 & 27.215 \\
\hline 290 & $\operatorname{cg} 08210706$ & 14 & 95046686 & SERPINA5 & 0.855 & 0.493 & 0.362 & 15.596 \\
\hline
\end{tabular}


(Cont. Supplementary Table 2)

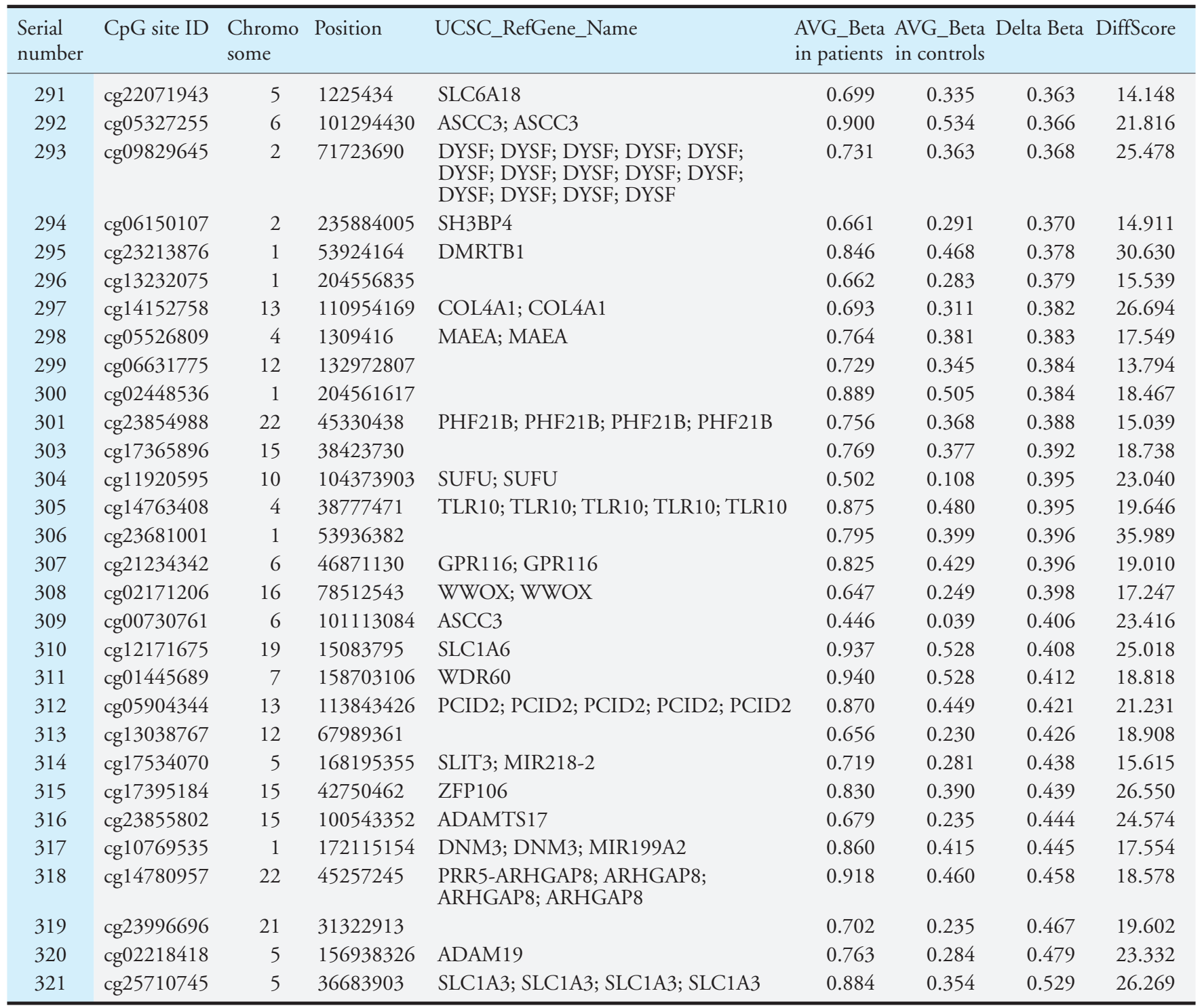


Supplementary Table 3. Changed methylation sites were assigned to 168 known gene regions

\begin{tabular}{|c|c|c|c|c|c|c|c|c|c|}
\hline $\begin{array}{l}\text { Serial } \\
\text { number }\end{array}$ & $\begin{array}{l}\text { UCSC_RefGene_ } \\
\text { Name }\end{array}$ & $\begin{array}{l}\text { Serial } \\
\text { number }\end{array}$ & $\begin{array}{l}\text { UCSC_RefGene_ } \\
\text { Name }\end{array}$ & $\begin{array}{l}\text { Serial } \\
\text { number }\end{array}$ & $\begin{array}{l}\text { UCSC_RefGene_ } \\
\text { Name }\end{array}$ & $\begin{array}{l}\text { Serial } \\
\text { number }\end{array}$ & $\begin{array}{l}\text { UCSC_RefGene_ } \\
\text { Name }\end{array}$ & $\begin{array}{l}\text { Serial } \\
\text { number }\end{array}$ & $\begin{array}{l}\text { UCSC_RefGene_ } \\
\text { Name }\end{array}$ \\
\hline 1 & C3orf50 & 35 & HLA-H & 69 & DLGAP1 & 103 & LINC00578 & 137 & DLG3 \\
\hline 2 & HEATR2 & 36 & CARS2 & 70 & АТР2C1 & 104 & RNF213 & 138 & GLP2R \\
\hline 3 & B3GLCT & 37 & GNA15 & 71 & ZDHHC4 & 105 & OSBPL5 & 139 & NID1 \\
\hline 4 & TAGLN3 & 38 & ANGPT2 & 72 & PTPRN2 & 106 & HLA-A & 140 & RHCE \\
\hline 5 & KIAA1026 & 39 & IFRD1 & 73 & MCM2 & 107 & MCF2L & 141 & PROZ \\
\hline 6 & CLDN4 & 40 & MSC-AS1 & 74 & INPP5B & 108 & SLC15A4 & 142 & ADRA1B \\
\hline 7 & PSTPIP2 & 41 & LINC00504 & 75 & C10orf47 & 109 & KRT23 & 143 & ADPRHL1 \\
\hline 8 & MEOX2 & 42 & TTC23 & 76 & KLK9 & 110 & MYOM2 & 144 & SPRED2 \\
\hline 9 & $\mathrm{ROBO} 1$ & 43 & TRAK2 & 77 & LOC101927730 & 111 & RABGAP1L & 145 & FSTL4 \\
\hline 10 & PPP1R16B & 44 & NCKIPSD & 78 & TNFSF8 & 112 & MAPK10 & 146 & YES1 \\
\hline 11 & BRDT & 45 & FOXK1 & 79 & ASTL & 113 & ZNF611 & 147 & SERPINA5 \\
\hline 12 & RNU6-71P & 46 & PRKCZ & 80 & PLD6 & 114 & SPAG1 & 148 & SLC6A18 \\
\hline 13 & COL6A2 & 47 & SORCS1 & 81 & KIRREL3 & 115 & HCG9 & 149 & DYSF \\
\hline 14 & ABHD12 & 48 & RNASEN & 82 & SLC6A12 & 116 & PTPRS & 150 & SH3BP4 \\
\hline 15 & SULF2 & 49 & SNX26 & 83 & MYT1L & 117 & LCT & 151 & DMRTB1 \\
\hline 16 & TANC1 & 50 & CHML & 84 & IL17RA & 118 & GZMK & 152 & COL4A1 \\
\hline 17 & PTGES & 51 & PGBD5 & 85 & LDB3 & 119 & FEZ2 & 153 & MAEA \\
\hline 18 & ALS2CR12 & 52 & PSD & 86 & SLC12A7 & 120 & DUSP27 & 154 & PHF21B \\
\hline 19 & ABI1 & 53 & SNTG2 & 87 & OSBPL10 & 121 & COPB1 & 155 & SUFU \\
\hline 20 & MPPED1 & 54 & ABCC9 & 88 & CCR2 & 122 & ST8SIA5 & 156 & TLR10 \\
\hline 21 & PFKP & 55 & FAM101A & 89 & LINC01252 & 123 & BNIP3 & 157 & GPR116 \\
\hline 22 & UBE2E2 & 56 & CNST & 90 & ODZ2 & 124 & MPPED2 & 158 & WwOX \\
\hline 23 & USPGNL & 57 & ARID1B & 91 & PITRM1 & 125 & UBA5 & 159 & SLC1A6 \\
\hline 24 & LINC01307 & 58 & COPS4 & 92 & CYFIP1 & 126 & C3orf20 & 160 & WDR60 \\
\hline 25 & APAF1 & 59 & ERLIN1 & 93 & SRPK3 & 127 & CYFIP2 & 161 & PCID2 \\
\hline 26 & BCAR3 & 60 & INADL & 94 & SORCS2 & 128 & TLR6 & 162 & SLIT3 \\
\hline 27 & RAB1A & 61 & GFPT2 & 95 & CPNE4 & 129 & NSF & 163 & ZFP106 \\
\hline 28 & LONRF2 & 62 & LAPTM5 & 96 & TNXB & 130 & GCK & 164 & ADAMTS17 \\
\hline 29 & FOLH1 & 63 & LOC101928358 & 97 & ATP8A2 & 131 & STXBP5-AS1 & 165 & DNM3 \\
\hline 30 & ADCK2 & 64 & DOK6 & 98 & INPP5A & 132 & RASA3 & 166 & ARHGAP8 \\
\hline 31 & MCC & 65 & GPR65 & 99 & IFT140 & 133 & SLC25A21 & 167 & ADAM19 \\
\hline 32 & EYA4 & 66 & NOTCH4 & 100 & SH3D19 & 134 & ZNF83 & 168 & SLC1A3 \\
\hline 33 & PUM1 & 67 & ASCC3 & 101 & CTSB & 135 & TIMP2 & & \\
\hline 34 & OR4L1 & 68 & C14orf126 & 102 & NRG3 & 136 & ADAM3A & & \\
\hline
\end{tabular}


Supplementary Table 4. Gene ontology enrichment analysis results of differentially methylated genes

\begin{tabular}{|c|c|c|c|c|c|c|c|c|}
\hline Term_ID & Term_description & Term_url & $\begin{array}{l}\text { Fold } \\
\text { Enrichment }\end{array}$ & Genes & GeneSymbols & $P_{-}$value & $\begin{array}{l}-\log 10 \\
\text { ( } p \text { value })\end{array}$ & FDR_bh \\
\hline GO:0070100 & $\begin{array}{l}\text { negative regulation of } \\
\text { chemokine-mediated } \\
\text { signaling pathway }\end{array}$ & $\begin{array}{l}\text { http://amigo.geneontology. } \\
\text { org/amigo/term/GO:0070100 }\end{array}$ & 46.052 & $6091 ; 6586$ & ROBO1; SLIT3 & 0.002 & 2.812 & 0.197 \\
\hline GO:0038096 & $\begin{array}{l}\text { Fc-gamma receptor signaling } \\
\text { pathway involved in } \\
\text { phagocytosis }\end{array}$ & $\begin{array}{l}\text { http://amigo.geneontology. } \\
\text { org/amigo/term/GO:0038096 }\end{array}$ & 6.257 & $\begin{array}{l}\text { 51517; 23191; 7525; } \\
10006 ; 26999\end{array}$ & $\begin{array}{l}\text { NCKIPSD; CYFIP1; } \\
\text { YES1; ABI1; CYFIP2 }\end{array}$ & 0.002 & 2.767 & 0.197 \\
\hline GO:0051346 & $\begin{array}{l}\text { negative regulation of } \\
\text { hydrolase activity }\end{array}$ & $\begin{array}{l}\text { http://amigo.geneontology. } \\
\text { org/amigo/term/GO:0051346 }\end{array}$ & 38.377 & $5590 ; 5104$ & PRKCZ; SERPINA5 & 0.002 & 2.689 & 0.197 \\
\hline GO:2000667 & $\begin{array}{l}\text { positive regulation of } \\
\text { interleukin-13 secretion }\end{array}$ & $\begin{array}{l}\text { http://amigo.geneontology. } \\
\text { org/amigo/term/GO:2000667 }\end{array}$ & 38.377 & $23765 ; 5590$ & IL17RA; PRKCZ & 0.002 & 2.689 & 0.197 \\
\hline GO:0048671 & $\begin{array}{l}\text { negative regulation of } \\
\text { collateral sprouting }\end{array}$ & $\begin{array}{l}\text { http://amigo.geneontology. } \\
\text { org/amigo/term/GO:0048671 }\end{array}$ & 38.377 & $23105 ; 3475$ & FSTL4; IFRD1 & 0.002 & 2.689 & 0.197 \\
\hline GO:0002224 & $\begin{array}{l}\text { toll-like receptor signaling } \\
\text { pathway }\end{array}$ & $\begin{array}{l}\text { http://amigo.geneontology. } \\
\text { org/amigo/term/GO:0002224 }\end{array}$ & 12.792 & $81793 ; 1508 ; 10333$ & TLR10; CTSB; TLR6 & 0.002 & 2.646 & 0.197 \\
\hline GO:0009611 & response to wounding & $\begin{array}{l}\text { http://amigo.geneontology. } \\
\text { org/amigo/term/GO:0009611 }\end{array}$ & 7.550 & $\begin{array}{l}55959 ; 6507 ; 11202 \\
729230\end{array}$ & $\begin{array}{l}\text { SULF2; SLC1A3; KLK8; } \\
\text { CCR2 }\end{array}$ & 0.003 & 2.587 & 0.197 \\
\hline GO:0048705 & $\begin{array}{l}\text { skeletal system } \\
\text { morphogenesis }\end{array}$ & $\begin{array}{l}\text { http://amigo.geneontology. } \\
\text { org/amigo/term/GO:0048705 }\end{array}$ & 11.513 & $9742 ; 144347 ; 51741$ & $\begin{array}{l}\text { IFT140; FAM101A; } \\
\text { WWOX }\end{array}$ & 0.003 & 2.526 & 0.197 \\
\hline GO:0071711 & $\begin{array}{l}\text { basement membrane } \\
\text { organization }\end{array}$ & $\begin{array}{l}\text { http://amigo.geneontology. } \\
\text { org/amigo/term/GO:0071711 }\end{array}$ & 28.783 & 4811 & NID1; COL4A1 & 0.003 & 2.488 & 0.197 \\
\hline GO:0006002 & $\begin{array}{l}\text { fructose 6-phosphate } \\
\text { metabolic process }\end{array}$ & $\begin{array}{l}\text { http://amigo.geneontology. } \\
\text { org/amigo/term/GO:0006002 }\end{array}$ & 28.783 & $5214 ; 9945$ & PFKP; GFPT2 & 0.003 & 2.488 & 0.197 \\
\hline GO:0002480 & $\begin{array}{l}\text { antigen processing and } \\
\text { presentation of exogenous } \\
\text { peptide antigen via MHC } \\
\text { class I, TAP-independent }\end{array}$ & $\begin{array}{l}\text { http://amigo.geneontology. } \\
\text { org/amigo/term/GO:0002480 }\end{array}$ & 25.585 & $3136 ; 3105$ & HLA-H; HLA-A & 0.004 & 2.404 & 0.197 \\
\hline GO:0010996 & response to auditory stimulus & $\begin{array}{l}\text { http://amigo.geneontology. } \\
\text { org/amigo/term/GO:0010996 }\end{array}$ & 25.585 & $51761 ; 26090$ & ATP8A2; ABHD12 & 0.004 & 2.404 & 0.197 \\
\hline GO:0032836 & $\begin{array}{l}\text { glomerular basement } \\
\text { membrane development }\end{array}$ & $\begin{array}{l}\text { http://amigo.geneontology. } \\
\text { org/amigo/term/GO:0032836 }\end{array}$ & 25.585 & $4811 ; 55959$ & NID1; SULF2 & 0.004 & 2.404 & 0.197 \\
\hline GO:0007165 & signal transduction & $\begin{array}{l}\text { http://amigo.geneontology. } \\
\text { org/amigo/term/GO:0007165 }\end{array}$ & 2.056 & $\begin{array}{l}8412 ; 5590 ; 10060 ; \\
10333 ; 51517 ; 51684 ; \\
9536 ; 9637 ; 3633 ; \\
22821 ; 23779 ; 285 ; \\
5602 ; 944 ; 8471 ; \\
5662 ; 4163 ; 1364 ; \\
27032\end{array}$ & $\begin{array}{l}\text { BCAR3; PRKCZ; } \\
\text { ABCC9; TLR6; } \\
\text { NCKIPSD; SUFU; } \\
\text { PTGES; FEZ2; INPP5B; } \\
\text { RASA3; ARHGAP8; } \\
\text { ANGPT2; MAPK10; } \\
\text { TNFSF8; IRS4; PSD; } \\
\text { MCC; CLDN4; ATP2C1 }\end{array}$ & 0.005 & 2.315 & 0.216 \\
\hline GO:0050707 & $\begin{array}{l}\text { regulation of cytokine } \\
\text { secretion }\end{array}$ & $\begin{array}{l}\text { http://amigo.geneontology. } \\
\text { org/amigo/term/GO:0050707 }\end{array}$ & 20.933 & $81793 ; 10333$ & TLR10; TLR6 & 0.006 & 2.257 & 0.216 \\
\hline GO:0019068 & virion assembly & $\begin{array}{l}\text { http://amigo.geneontology. } \\
\text { org/amigo/term/GO:0019068 }\end{array}$ & 20.933 & $9712 ; 5861$ & USP6NL; RAB1A & 0.006 & 2.257 & 0.216 \\
\hline GO:0090630 & activation of GTPase activity & $\begin{array}{l}\text { http://amigo.geneontology. } \\
\text { org/amigo/term/GO:0090630 }\end{array}$ & 5.981 & $\begin{array}{l}9712 ; 8477 ; 9910 \\
113622\end{array}$ & $\begin{array}{l}\text { USPGNL; GPR65; } \\
\text { RABGAP1L; ADPRHL1 }\end{array}$ & 0.006 & 2.245 & 0.216 \\
\hline GO:0007268 & $\begin{array}{l}\text { chemical synaptic } \\
\text { transmission }\end{array}$ & $\begin{array}{l}\text { http://amigo.geneontology. } \\
\text { org/amigo/term/GO:0007268 }\end{array}$ & 3.429 & $\begin{array}{l}\text { 10723; 6507; 9229; } \\
6539 ; 6511 ; 5802 ; \\
1741\end{array}$ & $\begin{array}{l}\text { SLC12A7; SLC1A3; } \\
\text { DLGAP1; SLC6A12; } \\
\text { SLC1A6; PTPRS; DLG3 }\end{array}$ & 0.006 & 2.223 & 0.216 \\
\hline GO:0035385 & $\begin{array}{l}\text { Roundabout signaling } \\
\text { pathway }\end{array}$ & $\begin{array}{l}\text { http://amigo.geneontology. } \\
\text { org/amigo/term/GO:0035385 }\end{array}$ & 19.189 & $6091 ; 6586$ & ROBO1; SLIT3 & 0.006 & 2.192 & 0.218 \\
\hline GO:0031338 & regulation of vesicle fusion & $\begin{array}{l}\text { http://amigo.geneontology. } \\
\text { org/amigo/term/GO:0031338 }\end{array}$ & 8.424 & $9712 ; 9910 ; 113622$ & $\begin{array}{l}\text { USP6NL; RABGAP1L; } \\
\text { ADPRHL1 }\end{array}$ & 0.007 & 2.172 & 0.218 \\
\hline GO:0089711 & $\begin{array}{l}\text { L-glutamate transmembrane } \\
\text { transport }\end{array}$ & $\begin{array}{l}\text { http://amigo.geneontology. } \\
\text { org/amigo/term/GO:0089711 }\end{array}$ & 17.712 & $6507 ; 6511$ & SLC1A3; SLC1A6 & 0.007 & 2.133 & 0.227 \\
\hline GO:0047496 & $\begin{array}{l}\text { vesicle transport along } \\
\text { microtubule }\end{array}$ & $\begin{array}{l}\text { http://amigo.geneontology. } \\
\text { org/amigo/term/GO:0047496 }\end{array}$ & 16.447 & $5861 ; 5590$ & RAB1A; PRKCZ & 0.008 & 2.077 & 0.246 \\
\hline GO:0031532 & $\begin{array}{l}\text { actin cytoskeleton } \\
\text { reorganization }\end{array}$ & $\begin{array}{l}\text { http://amigo.geneontology. } \\
\text { org/amigo/term/GO:0031532 }\end{array}$ & 7.349 & $8477 ; 5590 ; 27032$ & $\begin{array}{l}\text { GPR65; PRKCZ; } \\
\text { ATP2C1 }\end{array}$ & 0.010 & 2.019 & 0.262 \\
\hline
\end{tabular}


He et al.

(Cont. Supplementary Table 4)

\begin{tabular}{|c|c|c|c|c|c|c|c|c|}
\hline Term_ID & Term_description & Term_url & $\begin{array}{l}\text { Fold } \\
\text { Enrichment }\end{array}$ & Genes & GeneSymbols & $P_{\text {_value }}$ & $\begin{array}{l}-\log 10 \\
\text { ( } p \text { value })\end{array}$ & FDR_bh \\
\hline GO:0006508 & proteolysis & $\begin{array}{l}\text { http://amigo.geneontology. } \\
\text { org/amigo/term/GO:0006508 }\end{array}$ & 2.508 & $\begin{array}{l}431705 ; 3003 ; 10531 ; \\
51684 ; 170691 ; 2346 ; \\
164832 ; 1508 ; \\
284366 ; 11202\end{array}$ & $\begin{array}{l}\text { ASTL; GZMK; PITRM1; } \\
\text { SUFU; ADAMTS17; } \\
\text { FOLH1; LONRF2; } \\
\text { CTSB; KLK9; KLK8 }\end{array}$ & ; $\quad 0.010$ & 2.013 & 0.262 \\
\hline GO:0009416 & response to light stimulus & $\begin{array}{l}\text { http://amigo.geneontology. } \\
\text { org/amigo/term/GO:0009416 }\end{array}$ & 14.391 & $5602 ; 6507$ & MAPK10; SLC1A3 & 0.011 & 1.977 & 0.265 \\
\hline GO:0071560 & $\begin{array}{l}\text { cellular response to } \\
\text { transforming growth factor } \\
\text { beta stimulus }\end{array}$ & $\begin{array}{l}\text { http://amigo.geneontology. } \\
\text { org/amigo/term/GO:0071560 }\end{array}$ & 7.049 & $51741 ; 317 ; 7525$ & WWOX; APAF1; YES1 & 0.011 & 1.973 & 0.265 \\
\hline GO:0006886 & intracellular protein transport & $\begin{array}{l}\text { http://amigo.geneontology. } \\
\text { org/amigo/term/GO:0006886 }\end{array}$ & 3.353 & $\begin{array}{l}\text { 4905; 9712; 1122; } \\
9910 ; 1315 ; 113622\end{array}$ & $\begin{array}{l}\text { NSF; USP6NL; CHML; } \\
\text { RABGAP1L; COPB1; } \\
\text { ADPRHL1 }\end{array}$ & 0.012 & 1.937 & 0.278 \\
\hline GO:0007399 & nervous system development & $\begin{array}{l}\text { http://amigo.geneontology. } \\
\text { org/amigo/term/GO:0007399 }\end{array}$ & 2.909 & $\begin{array}{l}9637 ; 23040 ; 57492 ; \\
317 ; 744 ; 1741 ; 6091\end{array}$ & $\begin{array}{l}\text { FEZ2; MYT1L; } \\
\text { ARID1B; APAF1; } \\
\text { MPPED2; DLG3; } \\
\text { ROBO1 }\end{array}$ & 0.014 & 1.869 & 0.307 \\
\hline GO:0050790 & regulation of catalytic activity & $\begin{array}{l}\text { http://amigo.geneontology. } \\
\text { org/amigo/term/GO:0050790 }\end{array}$ & 6.280 & $26051 ; 1508 ; 23677$ & $\begin{array}{l}\text { PPP1R16B; CTSB; } \\
\text { SH3BP4 }\end{array}$ & 0.014 & 1.845 & 0.307 \\
\hline GO:0006811 & ion transport & $\begin{array}{l}\text { http://amigo.geneontology. } \\
\text { org/amigo/term/GO:0006811 }\end{array}$ & 4.386 & $\begin{array}{l}\text { 121260; 10723; 6507; } \\
6511\end{array}$ & $\begin{array}{l}\text { SLC15A4; SLC12A7; } \\
\text { SLC1A3; SLC1A6 }\end{array}$ & 0.016 & 1.805 & 0.307 \\
\hline GO:0046856 & $\begin{array}{l}\text { phosphatidylinositol } \\
\text { dephosphorylation }\end{array}$ & $\begin{array}{l}\text { http://amigo.geneontology. } \\
\text { org/amigo/term/GO:0046856 }\end{array}$ & 10.011 & $3633 ; 3632$ & INPP5B; INPP5A & 0.020 & 1.702 & 0.307 \\
\hline GO:0030574 & collagen catabolic process & $\begin{array}{l}\text { http://amigo.geneontology. } \\
\text { org/amigo/term/GO:0030574 }\end{array}$ & 5.397 & $1282 ; 1508 ; 1292$ & $\begin{array}{l}\text { COL4A1; CTSB; } \\
\text { COL6A2 }\end{array}$ & 0.021 & 1.679 & 0.307 \\
\hline GO:0006836 & neurotransmitter transport & $\begin{array}{l}\text { http://amigo.geneontology. } \\
\text { org/amigo/term/GO:0006836 }\end{array}$ & 9.594 & $6539 ; 348932$ & SLC6A12; SLC6A18 & 0.021 & 1.670 & 0.307 \\
\hline GO:0046580 & $\begin{array}{l}\text { negative regulation of Ras } \\
\text { protein signal transduction }\end{array}$ & $\begin{array}{l}\text { http://amigo.geneontology. } \\
\text { org/amigo/term/GO:0046580 }\end{array}$ & 9.210 & $22821 ; 7077$ & RASA3; TIMP2 & 0.023 & 1.639 & 0.307 \\
\hline GO:0003333 & $\begin{array}{l}\text { amino acid transmembrane } \\
\text { transport }\end{array}$ & $\begin{array}{l}\text { http://amigo.geneontology. } \\
\text { org/amigo/term/GO:0003333 }\end{array}$ & 9.210 & $6539 ; 348932$ & SLC6A12; SLC6A18 & 0.023 & 1.639 & 0.307 \\
\hline GO:0006891 & $\begin{array}{l}\text { intra-Golgi vesicle-mediated } \\
\text { transport }\end{array}$ & $\begin{array}{l}\text { http://amigo.geneontology. } \\
\text { org/amigo/term/GO:0006891 }\end{array}$ & 8.856 & $4905 ; 1315$ & NSF; COPB1 & 0.025 & 1.609 & 0.307 \\
\hline GO:0061621 & canonical glycolysis & $\begin{array}{l}\text { http://amigo.geneontology. } \\
\text { org/amigo/term/GO:0061621 }\end{array}$ & 8.856 & $2645 ; 5214$ & GCK; PFKP & 0.025 & 1.609 & 0.307 \\
\hline GO:0048010 & $\begin{array}{l}\text { vascular endothelial growth } \\
\text { factor receptor signaling } \\
\text { pathway }\end{array}$ & $\begin{array}{l}\text { http://amigo.geneontology. } \\
\text { org/amigo/term/GO:0048010 }\end{array}$ & 4.865 & 23191; 10006; 26999 & CYFIP1; ABI1; CYFIP2 & 0.027 & 1.567 & 0.307 \\
\hline GO:0001569 & patterning of blood vessels & $\begin{array}{l}\text { http://amigo.geneontology. } \\
\text { org/amigo/term/GO:0001569 }\end{array}$ & 8.224 & $1282 ; 4855$ & COL4A1; NOTCH4 & 0.028 & 1.553 & 0.307 \\
\hline GO:0014047 & glutamate secretion & $\begin{array}{l}\text { http://amigo.geneontology. } \\
\text { org/amigo/term/GO:0014047 }\end{array}$ & 8.224 & $6507 ; 6511$ & SLC1A3; SLC1A6 & 0.028 & 1.553 & 0.307 \\
\hline GO:0002474 & $\begin{array}{l}\text { antigen processing and } \\
\text { presentation of peptide } \\
\text { antigen via MHC class I }\end{array}$ & $\begin{array}{l}\text { http://amigo.geneontology. } \\
\text { org/amigo/term/GO:0002474 }\end{array}$ & 7.940 & $3136 ; 3105$ & HLA-H; HLA-A & 0.030 & 1.527 & 0.307 \\
\hline GO:0051402 & neuron apoptotic process & $\begin{array}{l}\text { http://amigo.geneontology. } \\
\text { org/amigo/term/GO:0051402 }\end{array}$ & 7.428 & $317 ; 664$ & APAF1; BNIP3 & 0.033 & 1.477 & 0.307 \\
\hline GO:0006890 & $\begin{array}{l}\text { retrograde vesicle-mediated } \\
\text { transport, Golgi to ER }\end{array}$ & $\begin{array}{l}\text { http://amigo.geneontology. } \\
\text { org/amigo/term/GO:0006890 }\end{array}$ & 4.428 & $4905 ; 5861 ; 1315$ & NSF; RAB1A; COPB1 & 0.034 & 1.467 & 0.307 \\
\hline GO:0002755 & $\begin{array}{l}\text { MyD88-dependent toll-like } \\
\text { receptor signaling pathway }\end{array}$ & $\begin{array}{l}\text { http://amigo.geneontology. } \\
\text { org/amigo/term/GO:0002755 }\end{array}$ & 7.196 & $81793 ; 10333$ & TLR10; TLR6 & 0.035 & 1.453 & 0.307 \\
\hline GO:0043588 & skin development & $\begin{array}{l}\text { http://amigo.geneontology. } \\
\text { org/amigo/term/GO:0043588 }\end{array}$ & 6.978 & $51761 ; 51684$ & ATP8A2; SUFU & 0.037 & 1.430 & 0.307 \\
\hline GO:0015758 & glucose transport & $\begin{array}{l}\text { http://amigo.geneontology. } \\
\text { org/amigo/term/GO:0015758 }\end{array}$ & 6.978 & $2645 ; 7525$ & GCK; YES1 & 0.037 & 1.430 & 0.307 \\
\hline GO:0006865 & amino acid transport & $\begin{array}{l}\text { http://amigo.geneontology. } \\
\text { org/amigo/term/GO:0006865 }\end{array}$ & 6.772 & $6539 ; 348932$ & SLC6A12; SLC6A18 & 0.039 & 1.407 & 0.307 \\
\hline GO:1902017 & regulation of cilium assembly & $\begin{array}{l}\text { http://amigo.geneontology. } \\
\text { org/amigo/term/GO:1902017 }\end{array}$ & 6.396 & $9712 ; 9742$ & USP6NL; IFT140 & 0.043 & 1.365 & 0.307 \\
\hline
\end{tabular}


(Cont. Supplementary Table 4)

\begin{tabular}{|c|c|c|c|c|c|c|c|c|}
\hline Term_ID & Term_description & Term_url & $\begin{array}{l}\text { Fold } \\
\text { Enrichment }\end{array}$ & Genes & GeneSymbols & $P_{-}$value & $\begin{array}{l}-\log 10 \\
(p \text { value })\end{array}$ & FDR_bh \\
\hline GO:0007188 & $\begin{array}{l}\text { adenylate cyclase-modulating } \\
\text { G-protein coupled receptor } \\
\text { signaling pathway }\end{array}$ & $\begin{array}{l}\text { http://amigo.geneontology. } \\
\text { org/amigo/term/GO:0007188 }\end{array}$ & 6.396 & $9340 ; 147$ & GLP2R; ADRA1B & 0.043 & 1.365 & 0.307 \\
\hline GO:0019882 & $\begin{array}{l}\text { antigen processing and } \\
\text { presentation }\end{array}$ & $\begin{array}{l}\text { http://amigo.geneontology. } \\
\text { org/amigo/term/GO:0019882 }\end{array}$ & 6.223 & $3136 ; 3105$ & HLA-H; HLA-A & 0.045 & 1.344 & 0.307 \\
\hline GO:0030154 & cell differentiation & $\begin{array}{l}\text { http://amigo.geneontology. } \\
\text { org/amigo/term/GO:0030154 }\end{array}$ & 2.093 & $\begin{array}{l}676 ; 2070 ; 23040 ; \\
7525 ; 4855 ; 221937 ; \\
317 ; 26576\end{array}$ & $\begin{array}{l}\text { BRDT; EYA4; MYT1L; } \\
\text { YES1; NOTCH4; } \\
\text { FOXK1; APAF1; SRPK3 }\end{array}$ & 0.046 & 1.337 & 0.307 \\
\hline GO:0010508 & $\begin{array}{l}\text { positive regulation of } \\
\text { autophagy }\end{array}$ & $\begin{array}{l}\text { http://amigo.geneontology. } \\
\text { org/amigo/term/GO:0010508 }\end{array}$ & 5.904 & $664 ; 23677$ & BNIP3; SH3BP4 & 0.050 & 1.305 & 0.307 \\
\hline
\end{tabular}


He et al.

Supplementary Table 5. Gene ontology enrichment analysis results for genes of the different sites near transcription start site

\begin{tabular}{|c|c|c|c|c|c|c|c|c|}
\hline Term_ID & Term_description & Term_url & $\begin{array}{l}\text { Fold } \\
\text { Enrichment }\end{array}$ & Genes & GeneSymbols & $P_{\text {_value }}$ & $\begin{array}{l}-\log 10 \\
(p \text { value })\end{array}$ & FDR_bh \\
\hline GO:0051346 & $\begin{array}{l}\text { negative regulation of } \\
\text { hydrolase activity }\end{array}$ & $\begin{array}{l}\text { http://amigo.geneontology. } \\
\text { org/amigo/term/GO:0051346 }\end{array}$ & 191.885 & $5590 ; 5104$ & PRKCZ; SERPINA5 & $9.24 \mathrm{E}-5$ & 4.034 & 0.017 \\
\hline GO:0009611 & response to wounding & $\begin{array}{l}\text { http://amigo.geneontology. } \\
\text { org/amigo/term/GO:0009611 }\end{array}$ & 28.311 & $\begin{array}{l}11202 ; 55959 \\
729230\end{array}$ & KLK8; SULF2; CCR2 & 0.000 & 3.616 & 0.023 \\
\hline GO:0031532 & $\begin{array}{l}\text { actin cytoskeleton } \\
\text { reorganization }\end{array}$ & $\begin{array}{l}\text { http://amigo.geneontology. } \\
\text { org/amigo/term/GO:0031532 }\end{array}$ & 24.496 & $8477 ; 5590$ & GPR65; PRKCZ & 0.004 & 2.434 & 0.103 \\
\hline GO:0006955 & immune response & $\begin{array}{l}\text { http://amigo.geneontology. } \\
\text { org/amigo/term/GO:0006955 }\end{array}$ & 6.753 & $\begin{array}{l}3136 ; 8477 ; 944 ; \\
729230\end{array}$ & $\begin{array}{l}\text { HLA-H; GPR65; } \\
\text { TNFSF8; CCR2 }\end{array}$ & 0.004 & 2.374 & 0.103 \\
\hline GO:0016525 & $\begin{array}{l}\text { negative regulation of } \\
\text { angiogenesis }\end{array}$ & $\begin{array}{l}\text { http://amigo.geneontology. } \\
\text { org/amigo/term/GO:0016525 }\end{array}$ & 19.514 & $285 ; 729230$ & ANGPT2; CCR2 & 0.006 & 2.248 & 0.103 \\
\hline GO:0008286 & $\begin{array}{l}\text { insulin receptor signaling } \\
\text { pathway }\end{array}$ & $\begin{array}{l}\text { http://amigo.geneontology. } \\
\text { org/amigo/term/GO:0008286 }\end{array}$ & 14.952 & $5590 ; 8471$ & PRKCZ; IRS4 & 0.009 & 2.032 & 0.103 \\
\hline GO:0002829 & $\begin{array}{l}\text { negative regulation of type } 2 \\
\text { immune response }\end{array}$ & $\begin{array}{l}\text { http://amigo.geneontology. } \\
\text { org/amigo/term/GO:0002829 }\end{array}$ & 115.131 & 729230 & CCR2 & 0.011 & 1.970 & 0.103 \\
\hline GO:0035860 & $\begin{array}{l}\text { glial cell-derived neurotrophic } \\
\text { factor receptor signaling } \\
\text { pathway }\end{array}$ & $\begin{array}{l}\text { http://amigo.geneontology. } \\
\text { org/amigo/term/GO:0035860 }\end{array}$ & 115.131 & 55959 & SULF2 & 0.011 & 1.970 & 0.103 \\
\hline GO:0043374 & $\begin{array}{l}\text { CD8-positive, alpha-beta } T \\
\text { cell differentiation }\end{array}$ & $\begin{array}{l}\text { http://amigo.geneontology. } \\
\text { org/amigo/term/GO:0043374 }\end{array}$ & 115.131 & 944 & TNFSF8 & 0.011 & 1.970 & 0.103 \\
\hline GO:0031584 & $\begin{array}{l}\text { activation of phospholipase } \mathrm{D} \\
\text { activity }\end{array}$ & $\begin{array}{l}\text { http://amigo.geneontology. } \\
\text { org/amigo/term/GO:0031584 }\end{array}$ & 95.943 & 5590 & PRKCZ & 0.012 & 1.904 & 0.103 \\
\hline GO:2000553 & $\begin{array}{l}\text { positive regulation of T-helper } \\
2 \text { cell cytokine production }\end{array}$ & $\begin{array}{l}\text { http://amigo.geneontology. } \\
\text { org/amigo/term/GO:2000553 }\end{array}$ & 95.943 & 5590 & PRKCZ & 0.012 & 1.904 & 0.103 \\
\hline GO:2000667 & $\begin{array}{l}\text { positive regulation of } \\
\text { interleukin-13 secretion }\end{array}$ & $\begin{array}{l}\text { http://amigo.geneontology. } \\
\text { org/amigo/term/GO:2000667 }\end{array}$ & 95.943 & 5590 & PRKCZ & 0.012 & 1.904 & 0.103 \\
\hline GO:0032020 & ISG15-protein conjugation & $\begin{array}{l}\text { http://amigo.geneontology. } \\
\text { org/amigo/term/GO:0032020 }\end{array}$ & 95.943 & 7325 & UBE2E2 & 0.012 & 1.904 & 0.103 \\
\hline GO:0018344 & protein geranylgeranylation & $\begin{array}{l}\text { http://amigo.geneontology. } \\
\text { org/amigo/term/GO:0018344 }\end{array}$ & 95.943 & 1122 & CHML & 0.012 & 1.904 & 0.103 \\
\hline GO:0048671 & $\begin{array}{l}\text { negative regulation of collateral } \\
\text { sprouting }\end{array}$ & $\begin{array}{l}\text { http://amigo.geneontology. } \\
\text { org/amigo/term/GO:0048671 }\end{array}$ & 95.943 & 3475 & IFRD1 & 0.012 & 1.904 & 0.103 \\
\hline GO:0048681 & $\begin{array}{l}\text { negative regulation of axon } \\
\text { regeneration }\end{array}$ & $\begin{array}{l}\text { http://amigo.geneontology. } \\
\text { org/amigo/term/GO:0048681 }\end{array}$ & 95.943 & 11202 & KLK8 & 0.012 & 1.904 & 0.103 \\
\hline GO:0015813 & L-glutamate transport & $\begin{array}{l}\text { http://amigo.geneontology. } \\
\text { org/amigo/term/GO:0015813 }\end{array}$ & 82.236 & 6511 & SLC1A6 & 0.014 & 1.846 & 0.103 \\
\hline GO:0031642 & $\begin{array}{l}\text { negative regulation of } \\
\text { myelination }\end{array}$ & $\begin{array}{l}\text { http://amigo.geneontology. } \\
\text { org/amigo/term/GO:0031642 }\end{array}$ & 82.236 & 11202 & KLK8 & 0.014 & 1.846 & 0.103 \\
\hline GO:0032049 & $\begin{array}{l}\text { cardiolipin biosynthetic } \\
\text { process }\end{array}$ & $\begin{array}{l}\text { http://amigo.geneontology. } \\
\text { org/amigo/term/GO:0032049 }\end{array}$ & 71.957 & 201164 & PLD6 & 0.016 & 1.795 & 0.103 \\
\hline GO:0002827 & $\begin{array}{l}\text { positive regulation of T-helper } \\
1 \text { type immune response }\end{array}$ & $\begin{array}{l}\text { http://amigo.geneontology. } \\
\text { org/amigo/term/GO:0002827 }\end{array}$ & 71.957 & 729230 & CCR2 & 0.016 & 1.795 & 0.103 \\
\hline GO:0045630 & $\begin{array}{l}\text { positive regulation of T-helper } \\
2 \text { cell differentiation }\end{array}$ & $\begin{array}{l}\text { http://amigo.geneontology. } \\
\text { org/amigo/term/GO:0045630 }\end{array}$ & 71.957 & 5590 & PRKCZ & 0.016 & 1.795 & 0.103 \\
\hline GO:0010954 & $\begin{array}{l}\text { positive regulation of protein } \\
\text { processing }\end{array}$ & $\begin{array}{l}\text { http://amigo.geneontology. } \\
\text { org/amigo/term/GO:0010954 }\end{array}$ & 71.957 & 431705 & ASTL & 0.016 & 1.795 & 0.103 \\
\hline GO:0007165 & signal transduction & $\begin{array}{l}\text { http://amigo.geneontology. } \\
\text { org/amigo/term/GO:0007165 }\end{array}$ & 3.246 & $\begin{array}{l}5590 ; 285 ; 5602 ; 944 ; \\
8471 ; 1364\end{array}$ & $\begin{array}{l}\text { PRKCZ; ANGPT2; } \\
\text { MAPK10; TNFSF8; } \\
\text { IRS4; CLDN4 }\end{array}$ & 0.017 & 1.772 & 0.103 \\
\hline GO:0002480 & $\begin{array}{l}\text { antigen processing and } \\
\text { presentation of exogenous } \\
\text { peptide antigen via MHC class } \\
\text { I, TAP-independent }\end{array}$ & $\begin{array}{l}\text { http://amigo.geneontology. } \\
\text { org/amigo/term/GO:0002480 }\end{array}$ & 63.962 & 3136 & HLA-H & 0.018 & 1.750 & 0.103 \\
\hline GO:0050807 & $\begin{array}{l}\text { regulation of synapse } \\
\text { organization }\end{array}$ & $\begin{array}{l}\text { http://amigo.geneontology. } \\
\text { org/amigo/term/GO:0050807 }\end{array}$ & 63.962 & 11202 & KLK8 & 0.018 & 1.750 & 0.103 \\
\hline GO:0010388 & cullin deneddylation & $\begin{array}{l}\text { http://amigo.geneontology. } \\
\text { org/amigo/term/GO:0010388 }\end{array}$ & 63.962 & 51138 & COPS4 & 0.018 & 1.750 & 0.103 \\
\hline GO:0046641 & $\begin{array}{l}\text { positive regulation of alpha- } \\
\text { beta } T \text { cell proliferation }\end{array}$ & $\begin{array}{l}\text { http://amigo.geneontology. } \\
\text { org/amigo/term/GO:0046641 }\end{array}$ & 63.962 & 729230 & CCR2 & 0.018 & 1.750 & 0.103 \\
\hline
\end{tabular}


(Cont. Supplementary Table 5)

\begin{tabular}{|c|c|c|c|c|c|c|c|c|}
\hline Term_ID & Term_description & Term_url & $\begin{array}{l}\text { Fold } \\
\text { Enrichment }\end{array}$ & Genes & GeneSymbols & $P_{\text {_value }}$ & $\begin{array}{l}-\log 10 \\
(p \text { value })\end{array}$ & FDR_bh \\
\hline GO:0032836 & $\begin{array}{l}\text { glomerular basement } \\
\text { membrane development }\end{array}$ & $\begin{array}{l}\text { http://amigo.geneontology. } \\
\text { org/amigo/term/GO:0032836 }\end{array}$ & 63.962 & 55959 & SULF2 & 0.018 & 1.750 & 0.103 \\
\hline GO:0003094 & glomerular filtration & $\begin{array}{l}\text { http://amigo.geneontology. } \\
\text { org/amigo/term/GO:0003094 }\end{array}$ & 57.566 & 55959 & SULF2 & 0.020 & 1.709 & 0.103 \\
\hline GO:0040037 & $\begin{array}{l}\text { negative regulation of } \\
\text { fibroblast growth factor } \\
\text { receptor signaling pathway }\end{array}$ & $\begin{array}{l}\text { http://amigo.geneontology. } \\
\text { org/amigo/term/GO:0040037 }\end{array}$ & 57.566 & 55959 & SULF2 & 0.020 & 1.709 & 0.103 \\
\hline GO:0030517 & $\begin{array}{l}\text { negative regulation of axon } \\
\text { extension }\end{array}$ & $\begin{array}{l}\text { http://amigo.geneontology. } \\
\text { org/amigo/term/GO:0030517 }\end{array}$ & 57.566 & 3475 & IFRD1 & 0.020 & 1.709 & 0.103 \\
\hline GO:0010820 & $\begin{array}{l}\text { positive regulation of } \mathrm{T} \text { cell } \\
\text { chemotaxis }\end{array}$ & $\begin{array}{l}\text { http://amigo.geneontology. } \\
\text { org/amigo/term/GO:0010820 }\end{array}$ & 57.566 & 729230 & CCR2 & 0.020 & 1.709 & 0.103 \\
\hline GO:0050732 & $\begin{array}{l}\text { negative regulation of } \\
\text { peptidyl-tyrosine } \\
\text { phosphorylation }\end{array}$ & $\begin{array}{l}\text { http://amigo.geneontology. } \\
\text { org/amigo/term/GO:0050732 }\end{array}$ & 52.332 & 5590 & PRKCZ & 0.021 & 1.671 & 0.103 \\
\hline GO:0035413 & $\begin{array}{l}\text { positive regulation of catenin } \\
\text { import into nucleus }\end{array}$ & $\begin{array}{l}\text { http://amigo.geneontology. } \\
\text { org/amigo/term/GO:0035413 }\end{array}$ & 52.332 & 55959 & SULF2 & 0.021 & 1.671 & 0.103 \\
\hline GO:0060081 & membrane hyperpolarization & $\begin{array}{l}\text { http://amigo.geneontology. } \\
\text { org/amigo/term/GO:0060081 }\end{array}$ & 52.332 & 5590 & PRKCZ & 0.021 & 1.671 & 0.103 \\
\hline GO:0042535 & $\begin{array}{l}\text { positive regulation of tumor } \\
\text { necrosis factor biosynthetic } \\
\text { process }\end{array}$ & $\begin{array}{l}\text { http://amigo.geneontology. } \\
\text { org/amigo/term/GO:0042535 }\end{array}$ & 52.332 & 729230 & CCR2 & 0.021 & 1.671 & 0.103 \\
\hline GO:0010447 & response to acidic $\mathrm{pH}$ & $\begin{array}{l}\text { http://amigo.geneontology. } \\
\text { org/amigo/term/GO:0010447 }\end{array}$ & 47.971 & 8477 & GPR65 & 0.023 & 1.637 & 0.103 \\
\hline GO:0007342 & $\begin{array}{l}\text { fusion of sperm to egg plasma } \\
\text { membrane }\end{array}$ & $\begin{array}{l}\text { http://amigo.geneontology. } \\
\text { org/amigo/term/GO:0007342 }\end{array}$ & 47.971 & 5104 & SERPINA5 & 0.023 & 1.637 & 0.103 \\
\hline GO:0019725 & cellular homeostasis & $\begin{array}{l}\text { http://amigo.geneontology. } \\
\text { org/amigo/term/GO:0019725 }\end{array}$ & 47.971 & 729230 & CCR2 & 0.023 & 1.637 & 0.103 \\
\hline GO:0043616 & keratinocyte proliferation & $\begin{array}{l}\text { http://amigo.geneontology. } \\
\text { org/amigo/term/GO:0043616 }\end{array}$ & 47.971 & 11202 & KLK8 & 0.023 & 1.637 & 0.103 \\
\hline GO:0043403 & $\begin{array}{l}\text { skeletal muscle tissue } \\
\text { regeneration }\end{array}$ & $\begin{array}{l}\text { http://amigo.geneontology. } \\
\text { org/amigo/term/GO:0043403 }\end{array}$ & 44.281 & 3475 & IFRD1 & 0.025 & 1.605 & 0.103 \\
\hline GO:0089711 & $\begin{array}{l}\text { L-glutamate transmembrane } \\
\text { transport }\end{array}$ & $\begin{array}{l}\text { http://amigo.geneontology. } \\
\text { org/amigo/term/GO:0089711 }\end{array}$ & 44.281 & 6511 & SLC1A6 & 0.025 & 1.605 & 0.103 \\
\hline GO:0046628 & $\begin{array}{l}\text { positive regulation of insulin } \\
\text { receptor signaling pathway }\end{array}$ & $\begin{array}{l}\text { http://amigo.geneontology. } \\
\text { org/amigo/term/GO:0046628 }\end{array}$ & 44.281 & 5590 & PRKCZ & 0.025 & 1.605 & 0.103 \\
\hline GO:0032743 & $\begin{array}{l}\text { positive regulation of } \\
\text { interleukin- } 2 \text { production }\end{array}$ & $\begin{array}{l}\text { http://amigo.geneontology. } \\
\text { org/amigo/term/GO:0032743 }\end{array}$ & 41.118 & 729230 & CCR2 & 0.027 & 1.576 & 0.103 \\
\hline GO:0047496 & $\begin{array}{l}\text { vesicle transport along } \\
\text { microtubule }\end{array}$ & $\begin{array}{l}\text { http://amigo.geneontology. } \\
\text { org/amigo/term/GO:0047496 }\end{array}$ & 41.118 & 5590 & PRKCZ & 0.027 & 1.576 & 0.103 \\
\hline GO:0002063 & chondrocyte development & $\begin{array}{l}\text { http://amigo.geneontology. } \\
\text { org/amigo/term/GO:0002063 }\end{array}$ & 41.118 & 55959 & SULF2 & 0.027 & 1.576 & 0.103 \\
\hline GO:0043537 & $\begin{array}{l}\text { negative regulation of blood } \\
\text { vessel endothelial cell } \\
\text { migration }\end{array}$ & $\begin{array}{l}\text { http://amigo.geneontology. } \\
\text { org/amigo/term/GO:0043537 }\end{array}$ & 41.118 & 285 & ANGPT2 & 0.027 & 1.576 & 0.103 \\
\hline GO:0010812 & $\begin{array}{l}\text { negative regulation of cell- } \\
\text { substrate adhesion }\end{array}$ & $\begin{array}{l}\text { http://amigo.geneontology. } \\
\text { org/amigo/term/GO:0010812 }\end{array}$ & 41.118 & 285 & ANGPT2 & 0.027 & 1.576 & 0.103 \\
\hline GO:0090026 & $\begin{array}{l}\text { positive regulation of } \\
\text { monocyte chemotaxis }\end{array}$ & $\begin{array}{l}\text { http://amigo.geneontology. } \\
\text { org/amigo/term/GO:0090026 }\end{array}$ & 38.377 & 729230 & CCR2 & 0.028 & 1.548 & 0.104 \\
\hline GO:0034587 & piRNA metabolic process & $\begin{array}{l}\text { http://amigo.geneontology. } \\
\text { org/amigo/term/GO:0034587 }\end{array}$ & 38.377 & 201164 & PLD6 & 0.028 & 1.548 & 0.104 \\
\hline GO:0070528 & protein kinase $\mathrm{C}$ signaling & $\begin{array}{l}\text { http://amigo.geneontology. } \\
\text { org/amigo/term/GO:0070528 }\end{array}$ & 38.377 & 5590 & PRKCZ & 0.028 & 1.548 & 0.104 \\
\hline GO:1990138 & neuron projection extension & $\begin{array}{l}\text { http://amigo.geneontology. } \\
\text { org/amigo/term/GO:1990138 }\end{array}$ & 35.978 & 5590 & PRKCZ & 0.030 & 1.522 & 0.104 \\
\hline GO:0009416 & response to light stimulus & $\begin{array}{l}\text { http://amigo.geneontology. } \\
\text { org/amigo/term/GO:0009416 }\end{array}$ & 35.978 & 5602 & MAPK10 & 0.030 & 1.522 & 0.104 \\
\hline GO:0002407 & dendritic cell chemotaxis & $\begin{array}{l}\text { http://amigo.geneontology. } \\
\text { org/amigo/term/GO:0002407 }\end{array}$ & 35.978 & 729230 & CCR2 & 0.030 & 1.522 & 0.104 \\
\hline
\end{tabular}


(Cont. Supplementary Table 5)

\begin{tabular}{|c|c|c|c|c|c|c|c|c|}
\hline Term_ID & Term_description & Term_url & $\begin{array}{l}\text { Fold } \\
\text { Enrichment }\end{array}$ & Genes & GeneSymbols & $P_{-}$value & $\begin{array}{l}-\log 10 \\
(p \text { value })\end{array}$ & FDR_bh \\
\hline GO:0031333 & $\begin{array}{l}\text { negative regulation of protein } \\
\text { complex assembly }\end{array}$ & $\begin{array}{l}\text { http://amigo.geneontology. } \\
\text { org/amigo/term/GO:0031333 }\end{array}$ & 33.862 & 5590 & PRKCZ & 0.032 & 1.498 & 0.104 \\
\hline GO:0061436 & establishment of skin barrier & $\begin{array}{l}\text { http://amigo.geneontology. } \\
\text { org/amigo/term/GO:0061436 }\end{array}$ & 33.862 & 1364 & CLDN4 & 0.032 & 1.498 & 0.104 \\
\hline GO:0043046 & $\begin{array}{l}\text { DNA methylation involved in } \\
\text { gamete generation }\end{array}$ & $\begin{array}{l}\text { http://amigo.geneontology. } \\
\text { org/amigo/term/GO:0043046 }\end{array}$ & 31.981 & 201164 & PLD6 & 0.034 & 1.475 & 0.104 \\
\hline GO:0050870 & $\begin{array}{l}\text { positive regulation of } \mathrm{T} \text { cell } \\
\text { activation }\end{array}$ & $\begin{array}{l}\text { http://amigo.geneontology. } \\
\text { org/amigo/term/GO:0050870 }\end{array}$ & 31.981 & 729230 & CCR2 & 0.034 & 1.475 & 0.104 \\
\hline GO:0008053 & mitochondrial fusion & $\begin{array}{l}\text { http://amigo.geneontology. } \\
\text { org/amigo/term/GO:0008053 }\end{array}$ & 31.981 & 201164 & PLD6 & 0.034 & 1.475 & 0.104 \\
\hline GO:2000463 & $\begin{array}{l}\text { positive regulation of } \\
\text { excitatory postsynaptic } \\
\text { potential }\end{array}$ & $\begin{array}{l}\text { http://amigo.geneontology. } \\
\text { org/amigo/term/GO:2000463 }\end{array}$ & 28.783 & 5590 & PRKCZ & 0.037 & 1.432 & 0.109 \\
\hline GO:1900087 & $\begin{array}{l}\text { positive regulation of } \mathrm{G} 1 / \mathrm{S} \\
\text { transition of mitotic cell cycle }\end{array}$ & $\begin{array}{l}\text { http://amigo.geneontology. } \\
\text { org/amigo/term/GO:1900087 }\end{array}$ & 28.783 & 7325 & UBE2E2 & 0.037 & 1.432 & 0.109 \\
\hline GO:0016338 & $\begin{array}{l}\text { calcium-independent cell-cell } \\
\text { adhesion via plasma membrane } \\
\text { cell-adhesion molecules }\end{array}$ & $\begin{array}{l}\text { http://amigo.geneontology. } \\
\text { org/amigo/term/GO:0016338 }\end{array}$ & 27.412 & 1364 & CLDN4 & 0.039 & 1.412 & 0.109 \\
\hline GO:0001954 & $\begin{array}{l}\text { positive regulation of cell- } \\
\text { matrix adhesion }\end{array}$ & $\begin{array}{l}\text { http://amigo.geneontology. } \\
\text { org/amigo/term/GO:0001954 }\end{array}$ & 27.412 & 5590 & PRKCZ & 0.039 & 1.412 & 0.109 \\
\hline GO:0007194 & $\begin{array}{l}\text { negative regulation of } \\
\text { adenylate cyclase activity }\end{array}$ & $\begin{array}{l}\text { http://amigo.geneontology. } \\
\text { org/amigo/term/GO:0007194 }\end{array}$ & 26.166 & 729230 & CCR2 & 0.040 & 1.393 & 0.109 \\
\hline GO:0007548 & sex differentiation & $\begin{array}{l}\text { http://amigo.geneontology. } \\
\text { org/amigo/term/GO:0007548 }\end{array}$ & 26.166 & 63948 & DMRTB1 & 0.040 & 1.393 & 0.109 \\
\hline GO:0030010 & establishment of cell polarity & $\begin{array}{l}\text { http://amigo.geneontology. } \\
\text { org/amigo/term/GO:0030010 }\end{array}$ & 23.986 & 5590 & PRKCZ & 0.044 & 1.358 & 0.109 \\
\hline GO:0007126 & meiotic nuclear division & $\begin{array}{l}\text { http://amigo.geneontology. } \\
\text { org/amigo/term/GO:0007126 }\end{array}$ & 23.986 & 201164 & PLD6 & 0.044 & 1.358 & 0.109 \\
\hline GO:0051090 & $\begin{array}{l}\text { regulation of sequence-specific } \\
\text { DNA binding transcription } \\
\text { factor activity }\end{array}$ & $\begin{array}{l}\text { http://amigo.geneontology. } \\
\text { org/amigo/term/GO:0051090 }\end{array}$ & 23.026 & 5602 & MAPK10 & 0.046 & 1.341 & 0.109 \\
\hline GO:0003333 & $\begin{array}{l}\text { amino acid transmembrane } \\
\text { transport }\end{array}$ & $\begin{array}{l}\text { http://amigo.geneontology. } \\
\text { org/amigo/term/GO:0003333 }\end{array}$ & 23.026 & 348932 & SLC6A18 & 0.046 & 1.341 & 0.109 \\
\hline GO:0010575 & $\begin{array}{l}\text { positive regulation of vascular } \\
\text { endothelial growth factor } \\
\text { production }\end{array}$ & $\begin{array}{l}\text { http://amigo.geneontology. } \\
\text { org/amigo/term/GO:0010575 }\end{array}$ & 22.141 & 55959 & SULF2 & 0.047 & 1.325 & 0.109 \\
\hline GO:0019216 & $\begin{array}{l}\text { regulation of lipid metabolic } \\
\text { process }\end{array}$ & $\begin{array}{l}\text { http://amigo.geneontology. } \\
\text { org/amigo/term/GO:0019216 }\end{array}$ & 22.141 & 8471 & IRS4 & 0.047 & 1.325 & 0.109 \\
\hline GO:0007616 & long-term memory & $\begin{array}{l}\text { http://amigo.geneontology. } \\
\text { org/amigo/term/GO:0007616 }\end{array}$ & 22.141 & 5590 & PRKCZ & 0.047 & 1.325 & 0.109 \\
\hline GO:0032148 & $\begin{array}{l}\text { activation of protein kinase } B \\
\text { activity }\end{array}$ & $\begin{array}{l}\text { http://amigo.geneontology. } \\
\text { org/amigo/term/GO:0032148 }\end{array}$ & 22.141 & 5590 & PRKCZ & 0.047 & 1.325 & 0.109 \\
\hline GO:0097421 & liver regeneration & $\begin{array}{l}\text { http://amigo.geneontology. } \\
\text { org/amigo/term/GO:0097421 }\end{array}$ & 21.321 & 55959 & SULF2 & 0.049 & 1.310 & 0.109 \\
\hline GO:0070979 & $\begin{array}{l}\text { protein K11-linked } \\
\text { ubiquitination }\end{array}$ & $\begin{array}{l}\text { http://amigo.geneontology. } \\
\text { org/amigo/term/GO:0070979 }\end{array}$ & 21.321 & 7325 & UBE2E2 & 0.049 & 1.310 & 0.109 \\
\hline
\end{tabular}


Supplementary Table 6. Kyoto Encyclopedia of Genes and Genomes pathway analysis results of differentially methylated genes

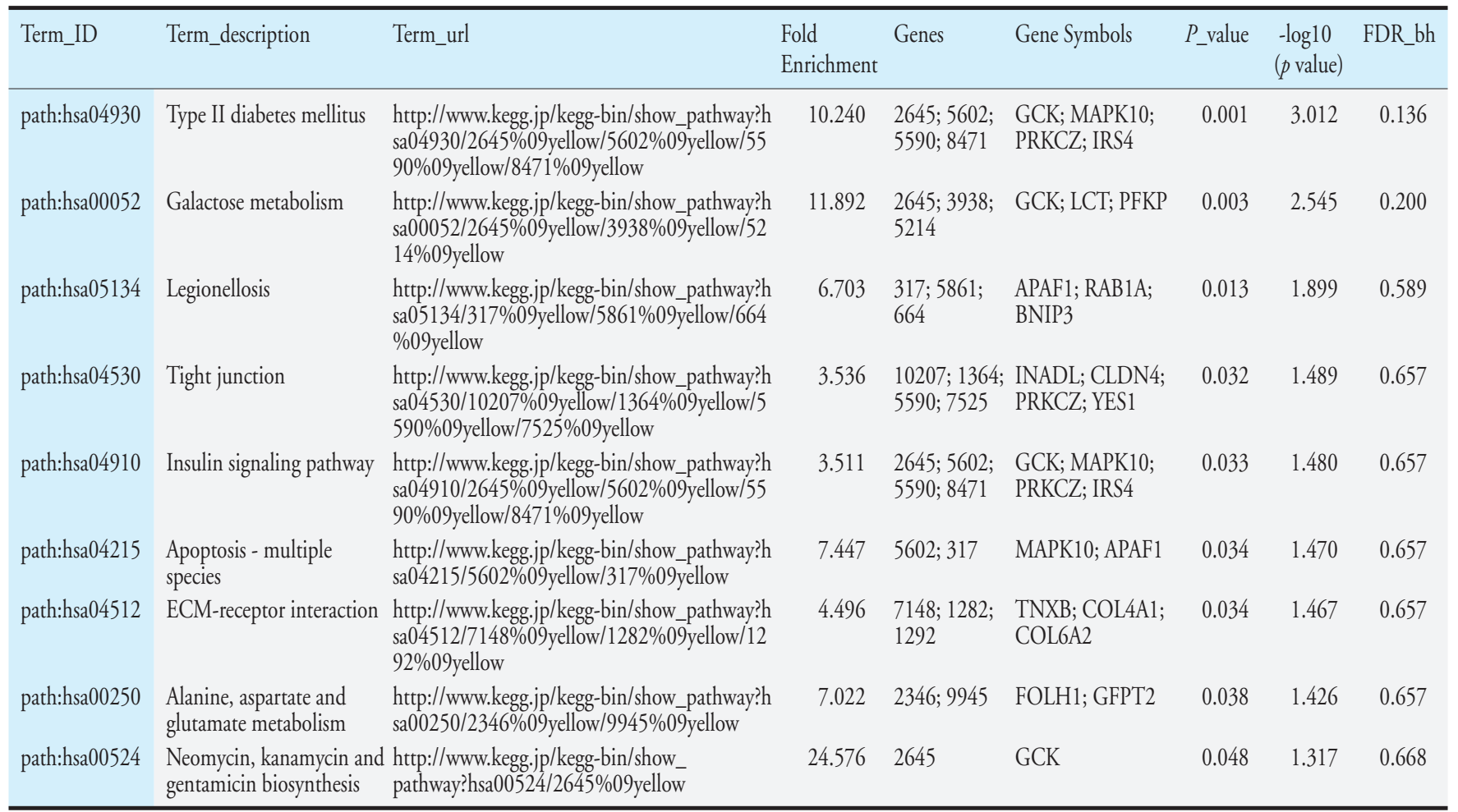

Supplementary Table 7. Kyoto Encyclopedia of Genes and Genomes pathway analysis results of genes of the different sites near transcription start site

\begin{tabular}{|c|c|c|c|c|c|c|c|c|}
\hline Term_ID & Term_description & Term_url & $\begin{array}{l}\text { Fold } \\
\text { Enrichment }\end{array}$ & Genes & Gene Symbols & $P_{-}$value & $\begin{array}{l}-\log 10 \\
(p \text { value })\end{array}$ & FDR_bh \\
\hline path:hsa04930 & Type II diabetes mellitus & $\begin{array}{l}\text { http://www.kegg.jp/kegg-bin/show_pathway?h } \\
\text { sa04930/5602\%09yellow/5590\%09yellow/84 } \\
\text { 71\%09yellow }\end{array}$ & 34.264 & $\begin{array}{l}5602 ; 5590 \\
8471\end{array}$ & $\begin{array}{l}\text { MAPK10; PRKCZ; } \\
\text { IRS4 }\end{array}$ & ; 0.000 & 3.754 & 0.012 \\
\hline path:hsa04910 & Insulin signaling pathway & $\begin{array}{l}\text { http://www.kegg.jp/kegg-bin/show_pathway?h } \\
\text { sa04910/5602\%09yellow/5590\%09yellow/84 } \\
\text { 71\%09yellow }\end{array}$ & 11.748 & $\begin{array}{l}5602 ; 5590 \\
8471\end{array}$ & $\begin{array}{l}\text { MAPK10; PRKCZ; } \\
\text { IRS4 }\end{array}$ & 0.003 & 2.463 & 0.119 \\
\hline path:hsa04933 & $\begin{array}{l}\text { AGE-RAGE signaling } \\
\text { pathway in diabetic } \\
\text { complications }\end{array}$ & $\begin{array}{l}\text { http://www.kegg.jp/kegg-bin/show_pathway?h } \\
\text { sa04933/5602\%09yellow/5590\%09yellow }\end{array}$ & 10.856 & $5602 ; 5590$ & MAPK10; PRKCZ & 0.019 & 1.730 & 0.254 \\
\hline path:hsa04931 & Insulin resistance & $\begin{array}{l}\text { http://www.kegg.jp/kegg-bin/show_pathway?h } \\
\text { sa04931/5602\%09yellow/5590\%09yellow }\end{array}$ & 10.059 & $5602 ; 5590$ & MAPK10; PRKCZ & 0.021 & 1.669 & 0.254 \\
\hline path:hsa04068 & FoxO signaling pathway & $\begin{array}{l}\text { http://www.kegg.jp/kegg-bin/show_pathway?h } \\
\text { sa04068/5602\%09yellow/8471\%09yellow }\end{array}$ & 8.183 & $5602 ; 8471$ & MAPK10; IRS4 & 0.031 & 1.508 & 0.254 \\
\hline path:hsa04530 & Tight junction & $\begin{array}{l}\text { http://www.kegg.jp/kegg-bin/show_pathway?h } \\
\text { sa04530/1364\%09yellow/5590\%09yellow }\end{array}$ & 7.888 & $1364 ; 5590$ & CLDN4; PRKCZ & 0.033 & 1.479 & 0.254 \\
\hline
\end{tabular}

